\title{
Replicating Business Cycles and Asset Returns with Sentiment and Low Risk Aversion
}

\author{
Kevin Lansing \\ Federal Reserve Bank of San Francisco \\ March 2023 \\ Working Paper 2021-02 \\ https://www.frbsf.org/economic-research/publications/working-papers/2021/02/
}

\section{Suggested citation:}

Lansing, Kevin. 2023 "Replicating Business Cycles and Asset Returns with Sentiment and Low Risk Aversion," Federal Reserve Bank of San Francisco Working Paper 202102. https://doi.org/10.24148/wp2021-02

The views in this paper are solely the responsibility of the authors and should not be interpreted as reflecting the views of the Federal Reserve Bank of San Francisco or the Board of Governors of the Federal Reserve System. 


\title{
Replicating Business Cycles and Asset Returns with Sentiment and Low Risk Aversion*
}

\author{
Kevin J. Lansing ${ }^{\dagger}$ \\ Federal Reserve Bank of San Francisco
}

March 2, 2023

\begin{abstract}
Using a real business cycle model, I solve for the sequences of shocks (or wedges) that allow the model to exactly replicate the quarterly time paths of U.S. macroeconomic variables and asset returns since 1960. Shocks that appear in the capital law of motion and shocks to equity sentiment are important drivers of movements in most U.S. variables and asset returns. But other shocks also play a significant role, particularly for lower frequency movements. The results imply that there is no "most important shock." Rather, U.S. economic outcomes have been shaped by a complex and time-varying mixture of fundamental and non-fundamental disturbances.
\end{abstract}

Keywords: Business cycle accounting, Sentiment, Animal spirits, Risk aversion, Equity risk premium, Bond term premium.

JEL Classification: E32, E44, O41.

*For helpful comments and suggestions, I thank Michal Andrle, Steve LeRoy, Jun Ma, and participants at the 2021 North American Summer Meeting of the Econometrics Society, the 2021 Barcelona GSE Summer Forum, the 2021 meeting of the Society for Computational Economics, and the 2021 meeting of the International Association of Applied Economics. Any opinions expressed here do not necessarily reflect the views of the Federal Reserve of Bank of San Francisco or the Board of Governors of the Federal Reserve System.

${ }^{\dagger}$ Research Department, Federal Reserve Bank of San Francisco, P.O. Box 7702, San Francisco, CA 941207702, kevin.j.lansing@sf.frb.org 


\section{Introduction}

The macroeconomics literature has not reached a consensus in identifying the most important forces driving U.S. business cycles. Chari, Kehoe, and McGrattan (2007) conclude that "efficiency wedges" (e.g., labor productivity shocks) and "labor supply wedges" (e.g., labor disutility shocks) are the main drivers of business cycles. Smets and Wouters (2007) find that shocks to labor productivity and wage mark-ups account for most of the fluctuations in output over the medium- to long-run. Justiniano, Primiceri, and Tambalotti (2010) conclude that an "investment shock" which appears in the law of motion for capital is the main driver of business cycle fluctuations in hours, output, and investment. Christiano, Motto, and Rostagno (2014) conclude that "risk shocks" (defined as the time-varying volatility of firms' idiosyncratic productivity realizations) are the most important business cycle shocks. Miao, Wang, and Xu (2015) find that a "sentiment shock" (which influences the size of a rational stock price bubble) together with labor productivity shocks and labor supply shocks are the most important business cycle shocks. Angeletos, Collard, and Dellas (2018) argue that "confidence shocks" (which are orthogonal to fundamental shocks and arise from agents' non-rational beliefs in the superior accuracy of their own productivity signals) are the main drivers of business cycles. In an empirical follow-up paper, Angeletos, Collard, and Dellas (2020) identify the "main business cycle shock" as a demand shock that does not strictly rely on nominal rigidity, consistent with a confidence- or sentiment-type shock.

The fact that so many different studies can reach different conclusions about the most important shock suggests that the conclusions are influenced by the type of model, or the type of data, employed in the exercise. It is worth noting that none of the studies mentioned above consider U.S. asset return data measuring the equity risk premium or the bond term premium. ${ }^{1}$ Moreover, none of these studies employ a model that allows for fluctuations in capital's share of income - a distinct feature of U.S. data. Numerous authors have demonstrated that factor distribution shocks can help to explain the equity risk premium in models with concentrated capital ownership. ${ }^{2}$

In this paper, I seek to identify the main drivers of U.S. business cycles and asset returns. As noted by Campbell, Pflueger, and Viceira (2020), requiring a unified description of both macroeconomics and asset pricing imposes valuable discipline on any model that seeks to explain the observed data. The framework for the analysis is a real business cycle model

\footnotetext{
${ }^{1}$ In estimating their model, Christiano, Motto, and Rostogno (2014) consider data on the value of the stock market, credit to nonfinancial firms, the credit spread of bond yields, and the term spread of bond yields. They evaluate their model using data on the cross-sectional dispersion of firm-level stock returns. In estimating their model, Miao, Wang, and Xu (2015) consider data on the value of the stock market and the Chicago Fed's National Financial Conditions Index (NFCI).

${ }^{2}$ See, for example, Danthine and Donaldson (2002), Guvenen (2009), Greenwald, Lettau, and Ludvigson (2022), Lansing (2015), and Gaudio, Petrella, and Santoro (2022).
} 
with eight fundamental shocks and one "equity sentiment shock" that captures belief-driven fluctuations. The eight fundamental shocks influence the representative agent's risk aversion coefficient, the disutility of labor supply, the productivity of three separate inputs that appear in the law of motion for capital, capital's share of income, the productivity of hours worked, and the real value of coupon payments from a long-term bond.

Three out of the nine model shocks, including the equity sentiment shock, can be classified as demand shocks. The remaining six shocks, including the labor disutility shock, can be classified as supply shocks. To facilitate the replication of U.S. asset return data, the model includes a time-varying risk aversion coefficient (motivated by external habit formation), a shock that influences the productivity of "investor effort" in the production of new capital, and a shock that influences the real value of bond coupon payments. These three shocks, together with equity sentiment, allow the model to exactly replicate quarterly U.S. data for the real return on equity (including dividends) and the real returns on both 1-period and long-term Treasury bonds. In so doing, the model exactly replicates quarterly U.S. data for the equity risk premium and the bond term premium.

Inclusion of the equity sentiment shock is motivated by a large literature that documents links between movements in equity prices and measures of investor or consumer sentiment. ${ }^{3}$ Numerous studies find evidence of a significant empirical link between non-fundamental equity price movements and the resulting investment decisions by firms. ${ }^{4}$ Recently, Bhandari, Borovička, and Ho (2019) and Bianchi, Ludvigson, and Ma (2022) present evidence that survey forecasts of economic activity fluctuate between optimism and pessimism and that these forecast fluctuations appear to be important drivers of the associated macroeconomic variables.

To identify the nine model shocks (or wedges), I employ a version of the "business cycle accounting" methodology developed by Chari, Kehoe, and McGrattan (2007). ${ }^{5}$ Other examples of this approach include Šustek (2011), Macnamara (2016), and Brinca, Chari, Kehoe, and McGrattan (2016), among others. But in contrast to these studies, the baseline model here is designed to replicate all movements in the U.S. data, not just those associated with business cycle frequencies. The sequences of the nine shocks are "reverse-engineered" so that the model exactly replicates the quarterly time paths of eleven macroeconomic variables and asset returns (only nine of which are independent). As an alternative to estimation, I calibrate

\footnotetext{
${ }^{3}$ See, for example, Baker and Wurgler (2007), Schmeling (2009), Greenwood and Shleifer (2014), Huang, et al. (2014), Adam, Marcet, and Beutel (2017), Frydman and Stillwagon (2018), and Lansing, LeRoy, and Ma (2022), among others.

${ }^{4}$ See, for example, Chirinko and Schaller (2001), Goyal and Yamada (2004), Gilchrist, Himmelberg, and Huberman (2005), and Campello and Graham (2013).

${ }^{5}$ Throughout the paper, I use the term "shocks" to describe the exogenous stochastic variables that appear in the model's equilibrium conditions.
} 
the model's parameters so that the steady state or trend values of the model variables exactly match the U.S. data in 1972.Q3 - a period when key U.S. macroeconomic ratios are all close to their full-sample means.

To simplify the shock identification exercise, I assume that the boundedly-rational representative agent in the model employs univariate forecast rules for each of the nine shocks. A fully-rational agent, in contrast, would employ a nine-dimensional vector autoregression (VAR) to forecast the future shock values. Use of the VAR would imply that the agent has knowledge of the complex correlation structure among the nine shock innovations. But this correlation structure can only be observed after the model itself is used to identify the shocks. I show that the use of an ex post estimated VAR instead of the univariate forecast rules delivers only modest improvements in the accuracy of the shock forecasts.

The sentiment shock in the model introduces a wedge between the agent's subjective forecast of future equity value and the "fundamentals-only" forecast. Due to the self-referential nature of the model and the near-unity slope of the intertemporal first order condition, the agent's perception that movements in equity value are partly driven by sentiment is close to self-fulfilling. The agent's forecast errors for future equity value are nearly identical those implied by a hypothetical model-consistent forecast. From the perspective of an individual agent, switching to the fundamentals-only forecast would appear to reduce forecast accuracy, so there is no incentive to switch.

The value of the model-identified sentiment shock is negative in steady state, implying that sentiment is "pessimistic" relative to fundamental equity value in 1972.Q3. This feature allows the model to replicate the equity risk premium in the data while maintaining a low level of risk aversion. Many studies show that incorporating some form of in-sample pessimistic bias about fundamentals or future equity values can magnify the equity risk premium in standard asset pricing models. ${ }^{6}$ The agent's "sentiment-adjusted" time discount factor resembles an analytical result derived by Gourio (2012) in which the agent's effective time discount factor is adjusted downward in the presence of disaster risk.

The typical business cycle accounting exercise delivers shocks (or wedges) that exhibit significant cross-correlations. ${ }^{7}$ I find strong positive correlations between shock innovations to sentiment, risk aversion, and labor disutility. I also find strong positive correlations between innovations to three separate shocks that appear in the capital law of motion. The first group of innovations is negatively correlated with the second group. The factor distribution shock and the labor productivity shock both appear in the aggregate production function. Innovations to these two shocks are negatively correlated with each other. For five out of nine

\footnotetext{
${ }^{6}$ See, for example, Reitz (1988), Cecchetti, Lam, and Mark (2000), Abel (2002), Cogley and Sargent (2008), Barro (2009), Gourio (2012), Bidder and Dew-Becker (2016), and Adam and Merkel (2019), among others.

${ }^{7}$ Using detrended quarterly U.S. data from 1959.Q1 to 2004.Q4, Chari, Kehoe, and McGrattan (2007, p. 810) report contemporaneous cross-correlations among their four model wedges that range from -0.88 to 0.61 .
} 
shocks, innovation volatility declines in the post-1984 sub-sample. But for the remaining four shocks, innovation volatility rises in the post-1984 sub-sample, particularly for the two shocks that appear in the aggregate production function. Overall, the results do not support the notion that macroeconomic or financial volatility has declined markedly in recent decades.
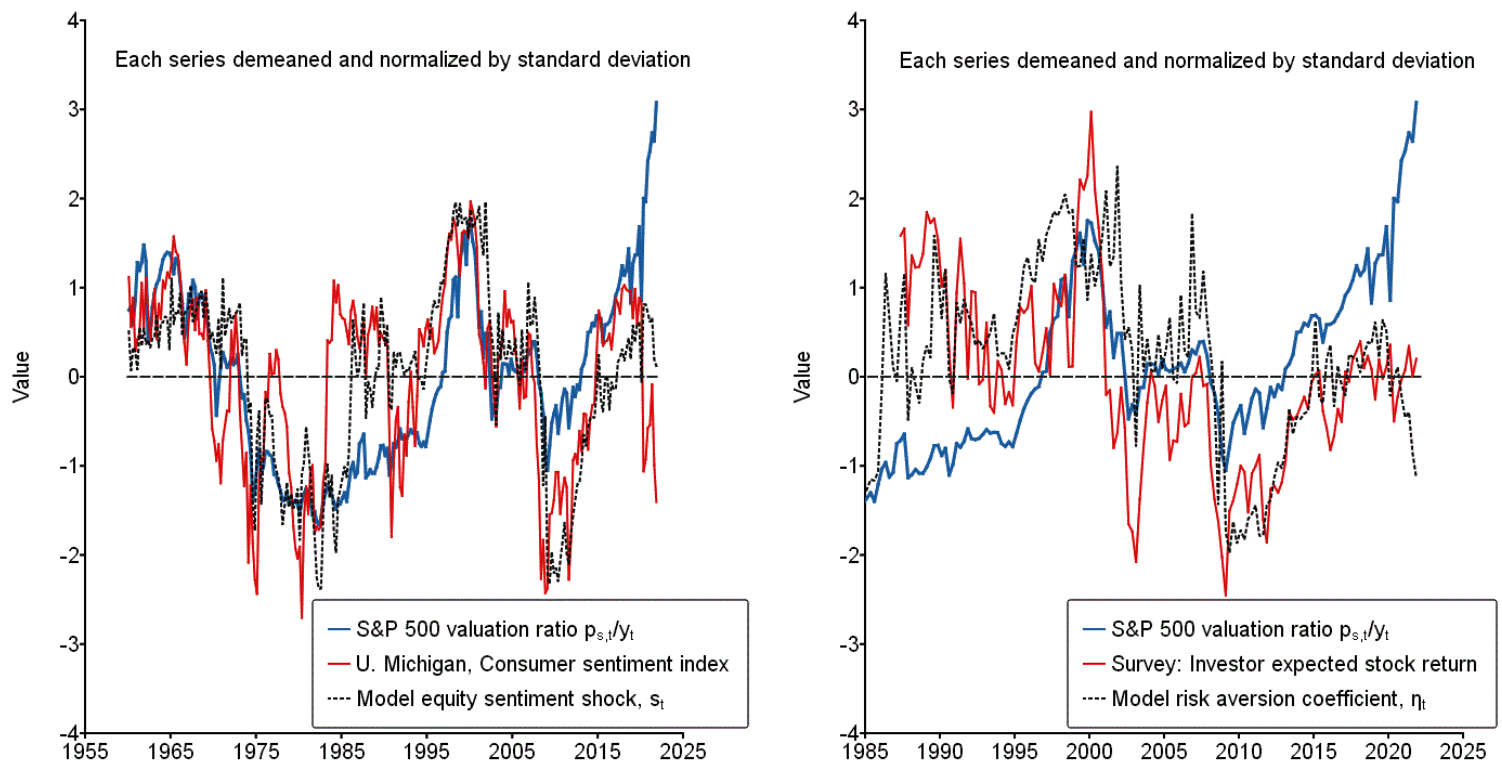

Figure 1: Model-identified sentiment and risk aversion

Notes: The model-identified sentiment shock (left panel) is strongly correlated with the University of Michigan's consumer sentiment index (which is not used in the shock identification procedure). Both series, in turn, are strongly correlated with a stock market valuation ratio defined as the nominal market capitalization of the S\&P 500 stock index divided by a measure of nominal output. The model-identified risk aversion coefficient (right panel) is strongly correlated with a survey-based measure of investors' expected stock returns over the next year from Nagel and Xu (2022a). Data series are described in Appendix D.

As a preview of the results, the left panel of Figure 1 plots the model-identified sentiment shock together with the University of Michigan's consumer sentiment index (which is not used in the shock identification procedure). The correlation coefficient between the two series is 0.65. Both series, in turn, are strongly correlated with a stock market valuation ratio defined as the nominal market capitalization of the Standard \& Poor's (S\&P) 500 stock index divided by a measure of nominal output.

The right panel of Figure 1 plots the model-identified risk aversion coefficient together with a survey-based measure of investors' expected return on stocks over the next year, as constructed by Nagel and $\mathrm{Xu}$ (2022a). The correlation coefficient between the two series 
is 0.59. Model-identified risk aversion is high when investors' expected return on stocks is high and when stock market valuation is also high. Higher model risk aversion is achieved when agents place more emphasis on interpersonal consumption comparisons during good times. This pattern provides a partial fundamental justification for investors' higher expected returns on stocks in good times. In contrast, models of rationally time-varying risk aversion deliver the exact opposite result: risk aversion and expected returns on stocks are both low in good times when stock market valuation is high (Campbell and Cochrane 1999). Numerous studies have demonstrated that investor survey evidence strongly contradicts the predictions of models with rationally time-varying risk aversion. ${ }^{8}$

Given the nine model-identified shock series, I perform the typical business cycle accounting exercise of feeding one or more sequences of shock realizations into the model when no other shock realizations are present. To gauge the importance of each shock, I compute various summary statistics. For fluctuations at business cycle frequencies, I compute the correlation coefficient between the detrended model variable under a given shock scenario and the detrended U.S. variable. To gauge the importance of each shock for lower frequency movements, I compute the cumulative growth impacts of a given shock scenario on key model variables starting from the steady state in 1972.Q3. I also compute the mean absolute gaps between counterfactual model paths that omit one or more sequences of shock realizations and the U.S. data paths, without any detrending.

The correlation coefficients between the model and the data show that shocks that appear in the capital law of motion and shocks to equity sentiment are important drivers of business cycle movements in most U.S. macroeconomic variables and asset returns. Shocks to risk aversion, the disutility of labor supply, and capital's share of income also play a significant role in these movements, but shocks to labor productivity do not. Multiple types of demand and supply shocks contribute to the decline in output during the Great Recession from 2007.Q4 to 2009.Q2. The decline in output during the Covid recession from 2019.Q4 to 2020.Q2 is driven almost entirely by two supply shocks that govern capital's share of income and the disutility of labor supply. For lower frequency movements, all of the model-identified shocks can be important, depending on which U.S. variables are being considered. Overall, the results imply that there is no "most important shock." Put another way, all nine shocks work together in allowing the model to exactly replicate the U.S. data. The following examples illustrate this idea.

According to the correlation coefficient rankings, the capital law of motion shocks are the most important drivers of business cycle movements in output. This result is in line with

${ }^{8}$ See, for example, Vissing-Jørgensen (2004), Amromin and Sharpe (2014), Greenwood and Shleifer (2014), Adam, Marcet, Beutel (2017), Giglio, et al. (2021), Adam, Matveev, and Nagel (2021), and Nagel and Xu (2022b). 
the findings of Justiniano, Primiceri, and Tambalotti (2010). But in contrast to their results, these same shocks are not the main drivers of business cycle movements in hours worked. Rather, this role is filled by the labor disutility shock, in line with the findings of Chari, Kehoe, and McGrattan (2007). But in stark contrast with the findings of Chari, Kehoe, and McGrattan (2007) and many other studies, I find that the labor productivity shock is not an important driver of business cycle movements in any variable. This result is due to the inclusion of the factor distribution shock which, according to the model, is the more important of the two shocks that appear in the aggregate production function. The models employed by Justiniano, Primiceri, and Tambalotti (2010) and Chari, Kehoe, and McGrattan (2007) do not allow for a factor distribution shock.

The equity sentiment shock is the most important driver of business cycle movements in investment, followed closely by the capital law of motion shocks. For consumption, the factor distribution shock and the risk aversion shock deliver the two largest correlation coefficients. For undetrended variables, the labor disutility shock is the main driver of movements in output, consumption, and hours worked. The equity sentiment shock is the main driver of movements in undetrended investment.

For asset returns, the capital law of motion shocks and the equity sentiment shock are the main drivers of movements in the equity return and the equity risk premium. Movements in the risk free rate are driven mainly by shocks to risk aversion and capital's share of income.

Since 1972.Q3, the factor distribution shock is by far the main driver of the cumulative growth effects in nearly all variables, including equity value. The result for equity value is consistent with the findings of Greenwald, Lettau, and Ludvigson (2022).

In discussing the difficulty of identifying a "main business cycle shock," Angeletos, Collard, and Dellas (2020, p. 3054) acknowledge "In principle, any of the reduced-form objects contained in our anatomy may map into a uninterpretable combination of multiple theoretical shocks..." The results presented here show that a complex combination of multiple theoretical shocks is indeed necessary to fully explain the historical patterns of U.S. business cycles and asset returns. Finding a simpler explanation for the historical patterns is likely to prove very difficult.

Additional related literature. The nine model-identified shocks should not be viewed as deep structural elements of the economy, but rather as Solow-type residuals that act as stand-ins for whatever time-varying model complexities are needed to replicate the U.S. data. The finding of significant cross-correlations among the nine shocks tells us that the model, as written, does not have sufficient detail to replicate the data using orthogonal shocks. But as discussed by Cúrdia and Reis (2011), Andrle (2014), and Andrle, Brůha, and Solmaz (2017), the cross-correlation pattern of the identified shocks can provide useful information about what may be needed to improve the model's fit via endogenous mechanisms. Falter and Wes- 
selbaum (2018) examine the impact of correlated shocks in the context of three benchmark macro models developed by Bernanke, Gertler, and Gilchrist (1999), Iacoviello (2005), and Justiniano, Primiceri, and Tambalotti (2010). In each case, the model with correlated shocks matches the data much better than the version with uncorrelated shocks. Along similar lines, Morely, Nelson, and Zivot (2003) document a significant negative correlation between innovations to the trend versus cycle components of U.S. GDP, in contrast to the orthogonal assumption embedded in most unobserved-component time series models. For models with multiple shocks and occasionally binding constraints, Ascari and Mavroeidis (2022) demonstrate that the existence of equilibrium requires interdependent restrictions on the support of the various shocks. This "coherency condition" is not compatible with the assumption of orthogonal shocks.

Layout. The remainder of this paper is organized as follows. Section 2 describes the model and the manner in which I introduce equity sentiment. Section 3 describes the identification of parameter values and the sequences of shock realizations so that the model exactly replicates quarterly U.S. data from 1960.Q1 to 2021.Q4. Section 4 presents quantitative exercises, including counterfactual shock scenarios. Section 5 concludes. The appendix provides details of the model solution, the shock identification procedure, and the data sources and methods.

\section{Model}

The framework for the analysis is a real business cycle model that includes eight fundamental shocks and one equity sentiment shock that captures belief-driven fluctuations. The representative agent's decision problem is to maximize

$$
\widehat{E}_{0} \sum_{t=0}^{\infty} \beta^{t}\left[\log \left(c_{t}-\kappa_{t} C_{t}\right)-D \exp \left(u_{t}\right) \frac{\left(h_{1, t}+h_{2, t}\right)^{1+\gamma}}{1+\gamma}\right],
$$

subject to the budget constraint

$$
c_{t}+i_{t}=w_{t} h_{1, t}+r_{t} k_{t}
$$

where $c_{t}$ is real consumption, $h_{1, t}$ is hours worked in the production of output, $h_{2, t}$ is hours worked in the production of new capital (called investor effort), $i_{t}$ is investment, $w_{t}$ is the real wage per hour, $r_{t}$ is the real rental rate per unit of capital, and $k_{t}$ is the stock of real physical capital. All quantities are measured in per person terms. The parameter $\beta>0$ is the agent's subjective time discount factor.

The symbol $\widehat{E}_{t}$ represents the agent's subjective expectation, conditional on information

available at time $t$. Under fully-rational expectations, $\widehat{E}_{t}$ corresponds to the mathematical expectation operator $E_{t}$ evaluated using the objective distribution of all shocks, which are 
assumed known to the fully-rational agent. I will also employ a "model-consistent" expectation operator $E_{t}^{m}$ that delivers forecasts consistent with the actual laws of motion of the relevant objects in the theoretical model. But as we shall see, the model-identified shocks from U.S. data are not orthogonal to each other as presumed by the theoretical model. Hence, $E_{t}^{m}$ must be viewed as boundedly-rational in the context of the data that the model seeks to replicate.

To allow for time-varying risk aversion, I assume that the representative agent derives utility from individual consumption $c_{t}$ measured relative to a reference level that depends on the amount of aggregate consumption per person $C_{t}$, which is viewed by the agent as exogenous. ${ }^{9}$ The reference level of consumption is often defined in terms of $C_{t-1}$ or $c_{t-1}$ as opposed to $C_{t} \cdot{ }^{10}$ But in the continuous-time limit, there is no distinction between the values of $C_{t}$ and $C_{t-1}$. Defining the reference level in terms of $C_{t}$ reduces the number of endogenous state variables and simplifies the equilibrium solution of the model without significantly influencing the identified shocks.

The time-varying parameter $\kappa_{t}$ determines the agent's subjective coefficient of relative risk aversion $\eta_{t}$ according to the relationship

$$
\begin{aligned}
\eta_{t} & \equiv-c_{t} \frac{U_{c c}\left(c_{t}, C_{t}\right)}{U_{c}\left(c_{t}, C_{t}\right)} \\
& =-c_{t} \frac{-1 /\left(c_{t}-\kappa_{t} C_{t}\right)^{2}}{1 /\left(c_{t}-\kappa_{t} C_{t}\right)}=\frac{1}{1-\kappa_{t}},
\end{aligned}
$$

where I have imposed the equilibrium condition $c_{t}=C_{t}$ in the second line of the expression. ${ }^{11}$ The agent's time-varying risk aversion coefficient evolves according to the following stationary law of motion

$$
\eta_{t}=\eta_{t-1}^{\rho_{\eta}} \bar{\eta}^{1-\rho_{\eta}} \exp \left(\varepsilon_{\eta, t}\right), \quad\left|\rho_{\eta}\right|<1, \quad \varepsilon_{\eta, t} \sim N I D\left(0, \sigma_{\varepsilon, \eta}^{2}\right)
$$

which ensures $\eta_{t}>0$. The parameter $\rho_{\eta}$ governs the persistence of the risk aversion coefficient and $\varepsilon_{\eta, t}$ is a normally and independently distributed (NID) innovation with mean zero and variance $\sigma_{\varepsilon, \eta}^{2}$. The steady state level of risk aversion is given by $\bar{\eta}$. For the quantitative analysis, I will employ $\bar{\eta}=1$ such that $\bar{\kappa}=0 .{ }^{12}$

The agent supplies labor to productive firms in the amount $h_{1, t}$. Following Zhu (1995), the agent also supplies "investor effort" in the amount $h_{2, t}$ that contributes to the production of

\footnotetext{
${ }^{9}$ Maurer and Meier (2008) find strong empirical evidence for contemporaneous "peer-group effects" on individual consumption decisions using panel data on U.S. household expenditures.

${ }^{10}$ See, for example, Otrok, Ravikumar and Whiteman (2002), Beaubrun-Diant and Tripier (2005), Christiano, Motto, and Rostagno (2014), and Lansing (2015).

${ }^{11}$ If the reference level of consumption is instead defined in terms of $C_{t-1}$, then the subjective risk aversion coefficient is given by $\eta_{t}=1 /\left(1-\kappa_{t} / g_{t}^{c}\right)$, where $g_{t}^{c} \equiv c_{t} / c_{t-1}$ is the gross growth rate of real consumption per person.

${ }^{12}$ Greenwald, Lettau, and Ludvigson (2022) develop a related model where the risk aversion coefficient and the risk free rate of return are each governed by an exogenous stochastic process.
} 
new capital, as described further below. The disutility of total labor supplied is governed by the second term in (1), where $D>0$, and $\gamma \geq 0$. The Frisch elasticity of labor supply is given by $1 / \gamma$. As $\gamma \rightarrow \infty$, the model reduces to one with fixed labor supply. Following Hall (1997), I allow for a "labor disutility shock" $u_{t}$ (also called a labor supply shock in the literature) that shifts the intratemporal trade-off between consumption and leisure. In support of this idea, Kaplan and Schulhofer-Wohl (2018) find that labor disutility, as measured by "feelings about work" from surveys, has shifted in significant ways since 1950. More generally, the shock $u_{t}$ could also be interpreted as a "labor wedge" that captures fluctuations in the effective tax rate on labor income. The labor disutility shock evolves according to the following stationary $\mathrm{AR}(1)$ process.

$$
u_{t}=\rho_{u} u_{t-1}+\varepsilon_{u, t}, \quad\left|\rho_{u}\right|<1, \quad \varepsilon_{u, t} \sim N I D\left(0, \sigma_{\varepsilon, u}^{2}\right)
$$

The representative agent derives income by supplying labor and capital services to identical competitive firms. Firms produce output according to the technology

$$
\begin{aligned}
y_{t} & =A k_{t}^{\alpha_{t}}\left[\exp \left(z_{t}\right) h_{1, t}\right]^{1-\alpha_{t}}, \quad A>0 \\
z_{t} & =z_{t-1}+\mu+\varepsilon_{z, t}, \quad \varepsilon_{z, t} \sim \operatorname{NID}\left(0, \sigma_{\varepsilon, z}^{2}\right) \\
\alpha_{t} & =\alpha_{t-1}^{\rho_{\alpha}} \bar{\alpha}^{1-\rho_{\alpha}} \exp \left(\varepsilon_{\alpha, t}\right), \quad\left|\rho_{\alpha}\right|<1, \quad \varepsilon_{\alpha, t} \sim \operatorname{NID}\left(0, \sigma_{\varepsilon, \alpha}^{2}\right) .
\end{aligned}
$$

In equation (6), $z_{t}$ represents a "labor productivity shock" that evolves as a random walk with drift. The drift parameter $\mu>0$ determines the trend growth rate of output per person in the economy. Stochastic variation in the production function exponent $\alpha_{t}$ represents a "factor distribution shock," along the lines of Young (2004), Ríos-Rull and Santaeulàlia-Llopis (2010), Lansing (2015), and Lansing and Markiewicz (2018). The logarithm of $\alpha_{t}$ evolves as a stationary $\operatorname{AR}(1)$ process.

Profit maximization by firms yields the factor prices

$$
\begin{aligned}
w_{t} & =\left(1-\alpha_{t}\right) y_{t} / h_{1, t}, \\
r_{t} & =\alpha_{t} y_{t} / k_{t},
\end{aligned}
$$

which together imply $y_{t}=w_{t} h_{1, t}+r_{t} k_{t}$. From equation (10), stochastic variation in $\alpha_{t}$ allows the model to replicate fluctuations in the U.S. capital share of income, as represented by $r_{t} k_{t} / y_{t}$. Given the time series for $\alpha_{t}$, stochastic variation in $z_{t}$ allows equation (6) to replicate fluctuations in U.S. output.

Resources devoted to investment together with investor effort contribute to the production 
of new capital according to the following law of motion

$$
\begin{array}{rlrlrl}
k_{t+1} & =B \exp \left(v_{t}\right) k_{t}^{1-\delta_{t}-\varphi_{t}} i_{t}^{\delta_{t}}\left[\exp \left(z_{t}\right) h_{2, t}\right]^{\varphi_{t}}, & B>0, & \\
v_{t} & =\rho_{v} v_{t-1}+\varepsilon_{v, t}, & & \left|\rho_{v}\right|<1, & \varepsilon_{v, t} \sim \operatorname{NID}\left(0, \sigma_{\varepsilon, v}^{2}\right), \\
\delta_{t}=\delta_{t-1}^{\rho_{\delta}} \bar{\delta}^{1-\rho_{\delta}} \exp \left(\varepsilon_{\delta, t}\right), & & \left|\rho_{\delta}\right|<1, & & \varepsilon_{\delta, t} \sim N I D\left(0, \sigma_{\varepsilon, \delta}^{2}\right), \\
\varphi_{t} & =\varphi_{t-1}^{\rho_{\varphi}} \bar{\varphi}^{1-\rho_{\varphi}} \exp \left(\varepsilon_{\varphi, t}\right), & & \left|\rho_{\varphi}\right|<1, & & \varepsilon_{\varphi, t} \sim N I D\left(0, \sigma_{\varepsilon, \varphi}^{2}\right),
\end{array}
$$

where the shocks $v_{t}, \delta_{t}$, and $\varphi_{t}$ can be interpreted as capturing financial frictions that impact the supply of new capital and the price of claims to existing capital. A study by Greenwood, Hercowitz, and Huffman (1988) was the first to demonstrate that shocks of this sort can be an important driving force for business cycle fluctuations. ${ }^{13}$ The log-linear formulation of equation (11) captures the presence of capital adjustment costs. ${ }^{14}$

Following Lansing and Markiewicz (2018), I allow for a "multiplier shock" $v_{t}$ that evolves as a stationary $\mathrm{AR}(1)$ process. Stochastic variation in $v_{t}$ allows equation (11) to replicate the time path of U.S. private nonresidential fixed assets. The variable $\delta_{t}$ is an "investment shock" that represents stochastic variation in the elasticity of new capital with respect to new investment. The variable $\varphi_{t}$ is an "investor effort shock" that represents stochastic variation in the elasticity of new capital with respect to investor effort. Analogous to equation (6), the productivity of investor effort is influenced by the labor productivity shock $z_{t}$. The logarithms of $\delta_{t}$ and $\varphi_{t}$ evolve as stationary $\mathrm{AR}(1)$ processes.

The agent's first-order conditions with respect to $c_{t}, h_{1, t}, h_{2, t}$, and $k_{t+1}$ are given by

$$
\begin{aligned}
& \lambda_{t}=1 /\left(c_{t}-\kappa_{t} C_{t}\right)=\eta_{t} / c_{t}, \\
& D \exp \left(u_{t}\right)\left(h_{1, t}+h_{2, t}\right)^{\gamma}=\lambda_{t} w_{t}, \\
& D \exp \left(u_{t}\right)\left(h_{1, t}+h_{2, t}\right)^{\gamma}=\lambda_{t} \varphi_{t} i_{t} /\left(\delta_{t} h_{2, t}\right), \\
& \lambda_{t} i_{t} /\left(\delta_{t} k_{t+1}\right)=\beta \widehat{E}_{t} \lambda_{t+1}\left[r_{t+1}+\left(1-\delta_{t+1}-\varphi_{t+1}\right) i_{t+1} /\left(\delta_{t+1} k_{t+1}\right)\right],
\end{aligned}
$$

where $\lambda_{t}$ is the Lagrange multiplier on the budget constraint (2). In equation (15), I have imposed the equilibrium relationships $c_{t}=C_{t}$ and $\eta_{t}=1 /\left(1-\kappa_{t}\right)$. In deriving equation (18), I start by using the capital law of motion (11) to eliminate $i_{t}$ from the budget constraint (2).

Combining equations (9), (16), and (17) yields the following expression for total hours worked $h_{t}$ :

$$
\underbrace{h_{1, t}+h_{2, t}}_{h_{t}}=\left\{\frac{\eta_{t}}{D \exp \left(u_{t}\right)}\left[\left(1-\alpha_{t}\right) \frac{y_{t}}{c_{t}}+\frac{\varphi_{t}}{\delta_{t}} \frac{i_{t}}{c_{t}}\right]\right\}^{1 /(1+\gamma)} .
$$

\footnotetext{
${ }^{13}$ Other examples along these lines include Ambler and Paquet (1994), Justiniano, Primiceri, and Tambalotti (2010), Liu, Waggoner, and Zha (2011), and Furlanetto and Seneca (2014).

${ }^{14}$ Lansing (2012) shows that equation (11) with $\varphi_{t}=0$ maps directly to a log-linear approximate version of the law of motion for capital employed by Jermann (1998).
} 
Given the time series for the shocks $\alpha_{t}, \eta_{t}, \delta_{t}$, and $\varphi_{t}$, stochastic variation in $u_{t}$ allows equation (19) to replicate the time path of U.S. hours worked per person.

Since $k_{t+1}$ is known at time $t$, equation (18) can be rewritten as follows

$$
\underbrace{i_{t} / \delta_{t}}_{p_{s, t}}=\widehat{E}_{t}\left\{M_{t+1}[\underbrace{\alpha_{t+1} y_{t+1}-\left(1+\varphi_{t+1} / \delta_{t+1}\right) i_{t+1}}_{d_{t+1}}+\underbrace{i_{t+1} / \delta_{t+1}}_{p_{s, t+1}}]\right\},
$$

where $M_{t+1} \equiv \beta\left(\eta_{t+1} / \eta_{t}\right)\left(c_{t+1} / c_{t}\right)^{-1}$ is the equilibrium stochastic discount factor. Notice that in steady state, the stochastic discount factor is given by $\bar{M} \equiv \beta \exp (-\mu)$, which does not depend on the steady state value $\bar{\eta}$.

The rewritten first-order condition (20) is in the form of a standard asset pricing equation where $p_{s, t}=i_{t} / \delta_{t}$ is the market value of the agent's equity shares in the firm. Equity shares are assumed to exist in unit net supply and entitle the agent to a perpetual stream of dividends $d_{t+1}$ starting in period $t+1$. From equations (16) and (17), we have $\varphi_{t} i_{t} / \delta_{t}=w_{t} h_{2, t}$. Dividends in period $t$ can therefore be written as

$$
d_{t}=\alpha_{t} y_{t}-i_{t}-w_{t} h_{2, t}
$$

which shows that the shadow wage bill for investor effort subtracts from the residual cash flow that can be paid out as dividends.

Stochastic variation in $\delta_{t}$ allows the model to replicate fluctuations in U.S. investment conditional on U.S. equity value. Stochastic variation in $\varphi_{t}$ allows the model to replicate fluctuations in U.S. dividends. Stochastic variation in an "equity sentiment shock" $s_{t}$ (introduced below) allows $p_{s, t}$ in the model to replicate fluctuations in the real market value of the S\&P 500 stock index. In so doing, the model's real equity return, given by $r_{s, t}=\left(p_{s, t}+d_{t}\right) / p_{s, t-1}-1$, replicates the real return on the $\mathrm{S} \& \mathrm{P} 500$ stock index.

In addition to equity shares, the representative agent can purchase default free bonds that exist in zero net-supply. One-period discount bonds purchased at the price $p_{b, t}$ yield a single payoff of one consumption unit per bond in period $t+1$. Long-term bonds (consols) purchased at the ex-coupon price $p_{c, t}$ yield a perpetual stream of stochastically-decaying coupon payments (measured in consumption units) starting in period $t+1$. The equilibrium prices of the bonds are determined by the following first-order conditions

$$
\begin{aligned}
& p_{b, t}=E_{t}^{m} M_{t+1}, \\
& p_{c, t}=E_{t}^{m} M_{t+1}\left[1+\bar{\delta}_{c} \exp \left(\omega_{t+1}\right) p_{c, t+1}\right],
\end{aligned}
$$

where $E_{t}^{m}$ implies that the agent's bond market forecasts are consistent with the actual laws of motion of the relevant objects in the theoretical model. Consequently, departures from model-consistent expectations are restricted to the equity market and these departures turn 
out to be very small. The variable $\delta_{c, t+1} \equiv \bar{\delta}_{c} \exp \left(\omega_{t+1}\right)$ is the stochastic decay rate of the coupon received in period $t+1$. The parameter $\bar{\delta}_{c} \in[0,1)$ is the steady state decay rate which influences the Macauly duration of the bond, i.e., the present-value weighted average maturity of the bond's cash flows. ${ }^{15}$ The shock $\omega_{t}$ captures stochastic variation in the real value of the bond coupon payment (for example, due to surprise inflation) and evolves according to the following stationary $\mathrm{AR}(1)$ process

$$
\omega_{t}=\rho_{\omega} \omega_{t-1}+\varepsilon_{\omega, t}, \quad\left|\rho_{\omega}\right|<1, \quad \varepsilon_{\omega, t} \sim N I D\left(0, \sigma_{\varepsilon, \omega}^{2}\right) .
$$

The model solutions for $p_{b, t}$ and $p_{c, t}$ are used to identify the sequences for the shocks $\eta_{t}$ and $\omega_{t}$. The risk free rate of return is given by $r_{b, t+1}=1 / p_{b, t}-1$, which is known at time $t$. Fluctuations in $\eta_{t}$ influence $M_{t+1}$ and thereby allow the model to replicate the real return on a 3-month U.S. Treasury bill. The risky return on the long-term bond is given by $r_{c, t+1}=$ $\left[1+\bar{\delta}_{c} \exp \left(\omega_{t+1}\right) p_{c, t+1}\right] / p_{c, t}-1$. Given the model-implied sequence for $M_{t+1}$, fluctuations in the coupon decay rate shock $\omega_{t}$ allow the model to replicate the real return on a long-term U.S. Treasury bond.

\subsection{Fundamental equity value}

Defining the risk adjusted equity value-consumption ratio (a stationary variable) as $x_{t} \equiv$ $\eta_{t} p_{s, t} / c_{t}=\eta_{t} i_{t} /\left(\delta_{t} c_{t}\right)$, the intertemporal first order condition (20) can be rewritten as follows

$$
\begin{aligned}
\underbrace{x_{t}}_{\eta_{t} p_{s, t} / c_{t}} & =\beta \widehat{E}_{t}\left\{\eta_{t+1} \alpha_{t+1} y_{t+1} / c_{t+1}+\left(1-\delta_{t+1}-\varphi_{t+1}\right) x_{t+1}\right\} \\
& =\beta \widehat{E}_{t}\{\underbrace{\eta_{t+1} \alpha_{t+1}+\left[1-\delta_{t+1}\left(1-\alpha_{t+1}\right)-\varphi_{t+1}\right] x_{t+1}}_{q_{t+1}}\},
\end{aligned}
$$

where I have substituted in for $M_{t+1}$ and collected terms dated $t$ on the left side. In the second line, I use the budget constraint (2) at time $t+1$ and the definition of $x_{t+1}$ to make the substitution $y_{t+1} / c_{t+1}=1+\delta_{t+1} x_{t+1} / \eta_{t+1}$.

At this point, it is convenient to define a nonlinear change of variables such that $q_{t+1}$ represents the composite stationary variable that the agent must forecast. ${ }^{16}$ The agent's first-order condition (24) becomes $x_{t}=\beta \widehat{E}_{t} q_{t+1}$. Now using the definition of $q_{t}$ to make the substitution $x_{t}=\left(q_{t}-\alpha_{t} \eta_{t}\right) /\left[1-\delta_{t}\left(1-\alpha_{t}\right)-\varphi_{t}\right]$ in equation (24) yields the following transformed version of the agent's first order condition

$$
q_{t}=\eta_{t} \alpha_{t}+\left[1-\delta_{t}\left(1-\alpha_{t}\right)-\varphi_{t}\right] \beta \widehat{E}_{t} q_{t+1} .
$$

${ }^{15}$ The stochastic stream of coupon payments is given by: $1, \bar{\delta}_{c} \exp \left(\omega_{t+1}\right), \bar{\delta}_{c}^{2} \exp \left(\omega_{t+1}+\omega_{t+2}\right), \bar{\delta}_{c}^{3} \exp \left(\omega_{t+1}+\right.$ $\left.\omega_{t+2}+\omega_{t+3}\right) \ldots$

${ }^{16}$ This nonlinear change of variables technique and the associated solution method is also employed in Lansing (2010, 2016) and Lansing and LeRoy (2014). 
The fundamental equity value is obtained by solving equation (25) under the assumption of model-consistent expectations such that $\widehat{E}_{t} q_{t+1}=E_{t}^{m} q_{t+1}$. As shown in Appendix A, a log-linear approximate version of the fundamental solution is given by

$$
q_{t}^{\mathrm{f}}=\bar{q}^{\mathrm{f}}\left[\frac{\eta_{t}}{\bar{\eta}}\right]^{\gamma_{\eta}}\left[\frac{\alpha_{t}}{\bar{\alpha}}\right]^{\gamma_{\alpha}}\left[\frac{\delta_{t}}{\bar{\delta}}\right]^{\gamma_{\delta}}\left[\frac{\varphi_{t}}{\bar{\varphi}}\right]^{\gamma_{\varphi}},
$$

where $\bar{q}^{\mathrm{f}} \equiv \exp \left[E_{t}^{m} \log \left(q_{t}^{\mathrm{f}}\right)\right]$ and $\gamma_{\eta}, \gamma_{\alpha}, \gamma_{\delta}$, and $\gamma_{\varphi}$ are solution coefficients that depend on model parameters and shock variances. Given the value of $q_{t}^{\mathrm{f}}$, we can recover the fundamental equity value-consumption ratio as

$$
\frac{p_{s, t}^{\mathrm{f}}}{c_{t}}=\frac{\left(q_{t}^{\mathrm{f}}-\alpha_{t}\right) / \eta_{t}}{1-\delta_{t}\left(1-\alpha_{t}\right)-\varphi_{t}},
$$

which shows that $p_{s, t}^{\mathrm{f}} / c_{t}$ will only move in response the four fundamental shocks $\eta_{t}, \alpha_{t}, \delta_{t}$, and $\varphi_{t}$.

\subsection{Introducing equity sentiment}

Pigou (1927, p. 73) attributed business cycle fluctuations partly to "psychological causes" which lead people to make "errors of undue optimism or undue pessimism in their business forecasts." Keynes (1936, p. 156) likened the stock market to a "beauty contest" where participants devote their efforts not to judging the underlying concept of beauty, but instead to "anticipating what average opinion expects the average opinion to be." Numerous empirical studies starting with Shiller (1981) and LeRoy and Porter (1981) have shown that equity prices appear to exhibit excess volatility when compared to fundamentals, as measured by the discounted stream of ex post realized dividends. ${ }^{17}$ Kocherlakota (2010) remarks: "I believe that [macroeconomists] are handicapping themselves by only looking at shocks to fundamentals like preferences and technology. Phenomena like credit market crunches or asset market bubbles rely on self-fulfilling beliefs about what others will do." 18

To capture the flavor of the above ideas, I postulate that the representative agent's perceived law of motion (PLM) for the composite variable $q_{t}$ allows for the possibility of departures from the fundamental value $q_{t}^{\mathrm{f}}$. Specifically, the agent's PLM takes the form

$$
\begin{aligned}
& q_{t}=\exp \left(s_{t}\right) q_{t}^{\mathrm{f}}, \\
& s_{t}=\bar{s}+\rho_{s}\left(s_{t-1}-\bar{s}\right)+\varepsilon_{s, t}, \quad\left|\rho_{s}\right|<1, \quad \varepsilon_{s, t} \sim N I D\left(0, \sigma_{\varepsilon, s}^{2}\right),
\end{aligned}
$$

\footnotetext{
${ }^{17}$ Lansing and LeRoy (2014) provide a recent update on this literature.

${ }^{18}$ There are a variety of ways in which sentiment or animal spirits-type mechanisms can be incorporated into quantitative business cycle models. For a brief review, see Lansing (2019).
} 
where the sentiment shock $s_{t}$ evolves as a stationary AR(1) process. The PLM predicts that $\log \left(q_{t} / q_{t}^{\mathrm{f}}\right)$ is increasing in $s_{t}$, where $q_{t}$ is the actual value observed in the data and $q_{t}^{\mathrm{f}}$ is the value predicted by fundamentals from equation (26).

Given the PLM (28), the agent's subjective forecast can be computed as follows

$$
\begin{aligned}
\widehat{E}_{t} q_{t+1}= & \exp \left[\bar{s}+\rho_{s}\left(s_{t}-\bar{s}\right)+\sigma_{\varepsilon, s}^{2} / 2\right] E_{t}^{m} q_{t+1}^{\mathrm{f}}, \\
= & \underbrace{\exp \left(\bar{s}+\sigma_{\varepsilon, s}^{2} / 2+\gamma_{\eta}^{2} \sigma_{\varepsilon, \eta}^{2} / 2+\gamma_{\alpha}^{2} \sigma_{\varepsilon, \alpha}^{2} / 2+\gamma_{\delta}^{2} \sigma_{\varepsilon, \delta}^{2} / 2+\gamma_{\delta}^{2} \sigma_{\varepsilon, \varphi}^{2} / 2\right) \bar{q}^{\mathrm{f}}}_{\bar{q}} \\
& \times \exp \left[\rho_{s}\left(s_{t}-\bar{s}\right)\right]\left[\frac{\eta_{t}}{\bar{\eta}}\right]^{\rho_{\eta} \gamma_{\eta}}\left[\frac{\alpha_{t}}{\bar{\alpha}}\right]^{\rho_{\alpha} \gamma_{\alpha}}\left[\frac{\delta_{t}}{\bar{\delta}}\right]^{\rho_{\delta} \gamma_{\delta}}\left[\frac{\varphi_{t}}{\bar{\varphi}}\right]^{\rho_{\varphi} \gamma_{\varphi}},
\end{aligned}
$$

where $E_{t}^{m} q_{t+1}^{\mathrm{f}}$ is the model-consistent "fundamentals-only" forecast that is computed from equation (26). From equation (30), we see that the term $\exp \left[\bar{s}+\rho_{s}\left(s_{t}-\bar{s}\right)+\sigma_{\varepsilon, s}^{2} / 2\right]$ acts as a wedge between the agent's subjective forecast and the fundamentals-only forecast. ${ }^{19}$ The basic structure of equation (30) is consistent with the empirical results of Frydman and Stillwagon (2018) who find that investors' expectations about future stock returns from surveys are jointly driven by fundamentals and behavioral factors.

The terms involving the sentiment shock in equation (30) can be combined with the time discount factor $\beta$ that appears in the transformed first order condition (25). This procedure yields the following "sentiment-adjusted" time discount factor

$$
\widehat{\beta}_{t} \equiv \beta \exp \left[\rho_{s} s_{t}+\left(1-\rho_{s}\right) \bar{s}+\sigma_{\varepsilon, s}^{2} / 2\right]
$$

which implies that $\widehat{\beta}_{t}$ is increasing in the value of $s_{t}$. When $\bar{s}<0$, the value of $\widehat{\beta}_{t}$ is lower than when $\bar{s} \geq 0$. The model with $\bar{s}<0$ resembles an analytical result derived by Gourio (2012, p. 2745) in which the agent's effective time discount factor is adjusted downward in the presence of disaster risk. ${ }^{20}$

Substituting the agent's subjective forecast (30) into the transformed first order condition (25) yields the actual law of motion (ALM) for $q_{t}$. The first order condition is "self-referential," meaning that the actual value of $q_{t}$ depends in part on the agent's subjective forecast $\widehat{E}_{t} q_{t+1}$. When $\eta_{t} \simeq 0$, equation (25) resembles a rational bubble condition for which there exists a continuum of self-fulfilling solutions. ${ }^{21}$ But even when $\eta_{t}>0$, the actual value of $q_{t}$ can closely

\footnotetext{
${ }^{19} \mathrm{Yu}(2013)$ introduces a persistent sentiment shock that acts as a wedge between the actual versus perceived laws of motion for consumption growth in an endowment economy.

${ }^{20}$ Albuquerque, et al. (2016) develop a fully-rational asset pricing model of an endowment economy with "time preference shocks." These shocks help to explain the equity premium when the agent's risk aversion coefficient and elasticity of intertemporal substitution are both greater than one or both smaller than one.

${ }^{21}$ Lansing (2010) provides examples of rational bubble solutions in an endowment economy.
} 
approximate the value predicted by the PLM (28) if the slope coefficient applied to $\widehat{E}_{t} q_{t+1}$ in equation (25) is close to 1.0. I will show that this near-unity property of the slope coefficient is satisfied in the quantitative version of the model. Consequently, the agent's perception that movements in equity value are partly driven by sentiment is close to self-fulfilling. The agent's subjective forecast errors are close to white noise with near-zero mean, providing no obvious signal that the sentiment-based forecast rule (30) is misspecified.

Given the realized value of $q_{t}$, we can recover the equity value-consumption ratio as

$$
\frac{p_{s, t}}{c_{t}}=\frac{\left(q_{t}-\alpha_{t}\right) / \eta_{t}}{1-\delta_{t}\left(1-\alpha_{t}\right)-\varphi_{t}},
$$

where $q_{t}=q\left(\eta_{t}, \alpha_{t}, \delta_{t}, \varphi_{t}, s_{t}\right)$. Hence in equilibrium, $p_{s, t} / c_{t}$ will be partly driven by sentiment because the agent's subjective forecast (30) makes use of the sentiment variable. Using equation (32), we can recover the risk adjusted equity value-consumption ratio as

$$
x_{t} \equiv \frac{\eta_{t} p_{s, t}}{c_{t}}=\frac{\eta_{t} i_{t}}{\delta_{t} c_{t}}=\frac{q_{t}-\alpha_{t}}{1-\delta_{t}\left(1-\alpha_{t}\right)-\varphi_{t}}
$$

where $x_{t}=x\left(\eta_{t}, \alpha_{t}, \delta_{t}, \varphi_{t}, s_{t}\right)$. Alternatively, since $x_{t}=\beta \widehat{E}_{t} q_{t+1}$, we can recover $x_{t}$ by multiplying the agent's subjective forecast (30) by $\beta$.

\subsection{Equilibrium macroeconomic variables and asset returns}

Given the value of $x_{t}$ from equation (33), the equilibrium values of the other macroeconomic variables can be computed using the following equations

$$
\begin{aligned}
h_{t} & =\left\{D^{-1} \exp \left(-u_{t}\right)\left[\left(1-\alpha_{t}\right)\left(\eta_{t}+\delta_{t} x_{t}\right)+\varphi_{t} x_{t}\right]\right\}^{1 /(1+\gamma)}, \\
h_{1, t} & =\left\{\left[\left(1-\alpha_{t}\right)\left(\eta_{t}+\delta_{t} x_{t}\right)\right] /\left[\left(1-\alpha_{t}\right)\left(\eta_{t}+\delta_{t} x_{t}\right)+\varphi_{t} x_{t}\right]\right\} h_{t}, \\
h_{2, t} & =\left\{\varphi_{t} x_{t} /\left[\left(1-\alpha_{t}\right)\left(\eta_{t}+\delta_{t} x_{t}\right)+\varphi_{t} x_{t}\right]\right\} h_{t}, \\
y_{t} & =A k_{t}^{\alpha_{t}}\left[\exp \left(z_{t}\right) h_{1, t}\right]^{1-\alpha_{t}} \\
c_{t} & =\left[\eta_{t} /\left(\eta_{t}+\delta_{t} x_{t}\right)\right] y_{t}, \\
i_{t} & =\left[\delta_{t} x_{t} /\left(\eta_{t}+\delta_{t} x_{t}\right)\right] y_{t}, \\
p_{t}^{s} & =i_{t} / \delta_{t} \\
d_{t} & =\alpha_{t} y_{t}-\left(1+\varphi_{t} / \delta_{t}\right) i_{t}
\end{aligned}
$$

where I have made use of equation (19) and the budget relationships $y_{t} / c_{t}=1+\delta_{t} x_{t} / \eta_{t}$, and $i_{t} / c_{t}=\delta_{t} x_{t} / \eta_{t}$.

Notice that the factor distribution shock $\alpha_{t}$ appears either directly or indirectly in equations (34) through (41). Efforts to explain movements in these variables using an otherwise 
similar model with $\alpha_{t}=\bar{\alpha}$ for all $t$ could therefore distort the importance of the other model shocks.

The equilibrium paths of $p_{s, t}$ and $d_{t}$ pin down the real equity return $r_{s, t}$. The equilibrium paths of the bond prices $p_{b, t}$ and $p_{c, t}$ are obtained by solving equations (22) and (23). The solutions, which pin down the real bond returns $r_{b, t}$ and $r_{c, t}$, are contained in Appendix B.
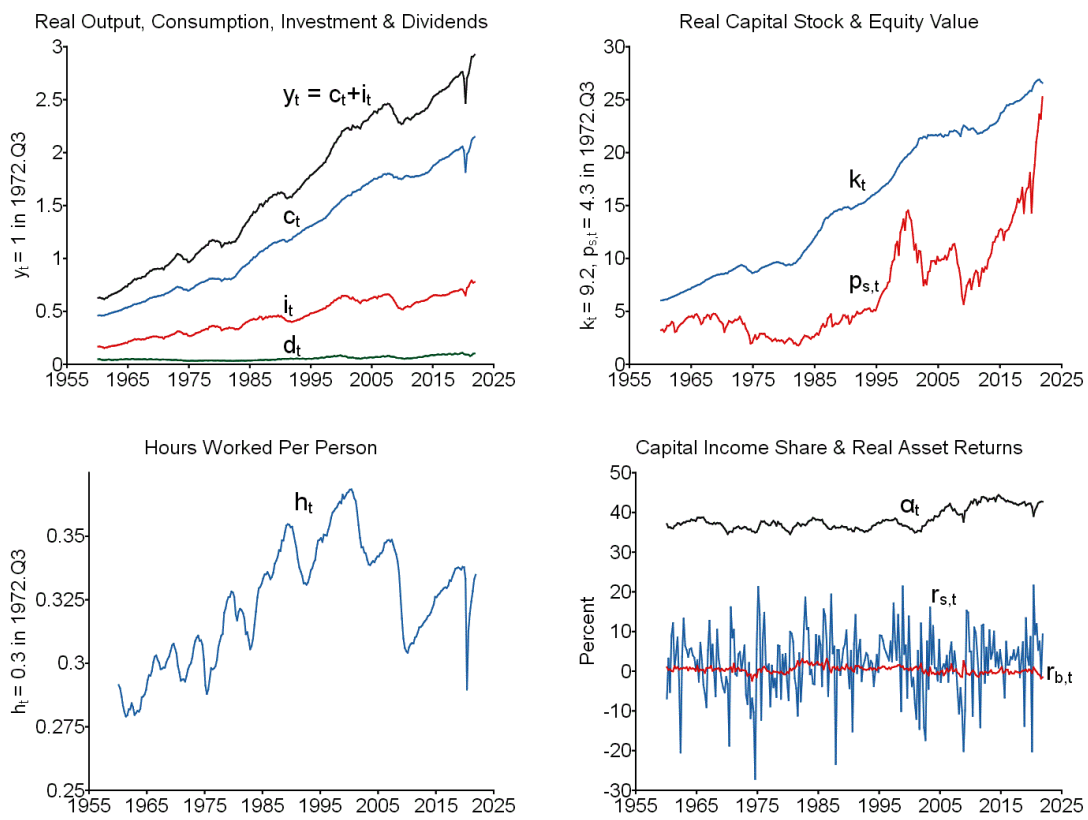

Figure 2: U.S. macroeconomic variables and asset returns

Notes: The baseline model exactly replicates the quarterly time paths of all ten U.S. variables plotted above plus the real return on a long-term U.S. government bond from 1960 to 2021. Data series are described in Appendix D.

\section{Parameter values and model-identified shocks}

Figure 2 plots the U.S. data versions of ten model variables. The sources and methods used to construct these variables, plus the long-term bond return, are described in Appendix D. Figure 3 plots the U.S. data versions of the ratios $c_{t} / y_{t}, i_{t} / y_{t}, k_{t} / y_{t}$, and $p_{s, t} / y_{t}$. These ratios are all close to their full-sample means in 1972.Q3. As an alternative to estimation, I calibrate parameter values so that the steady state or trend values of the model variables are exactly equal to the values observed in the data in 1972.Q3. ${ }^{22}$

\footnotetext{
${ }^{22}$ Many studies, such as Smets and Wouters (2007), Christiano, Motto, and Rostagno (2014), and Miao, Wang, and Xu (2015) employ a combination of calibration and estimation to pin down their model's parameter
} 

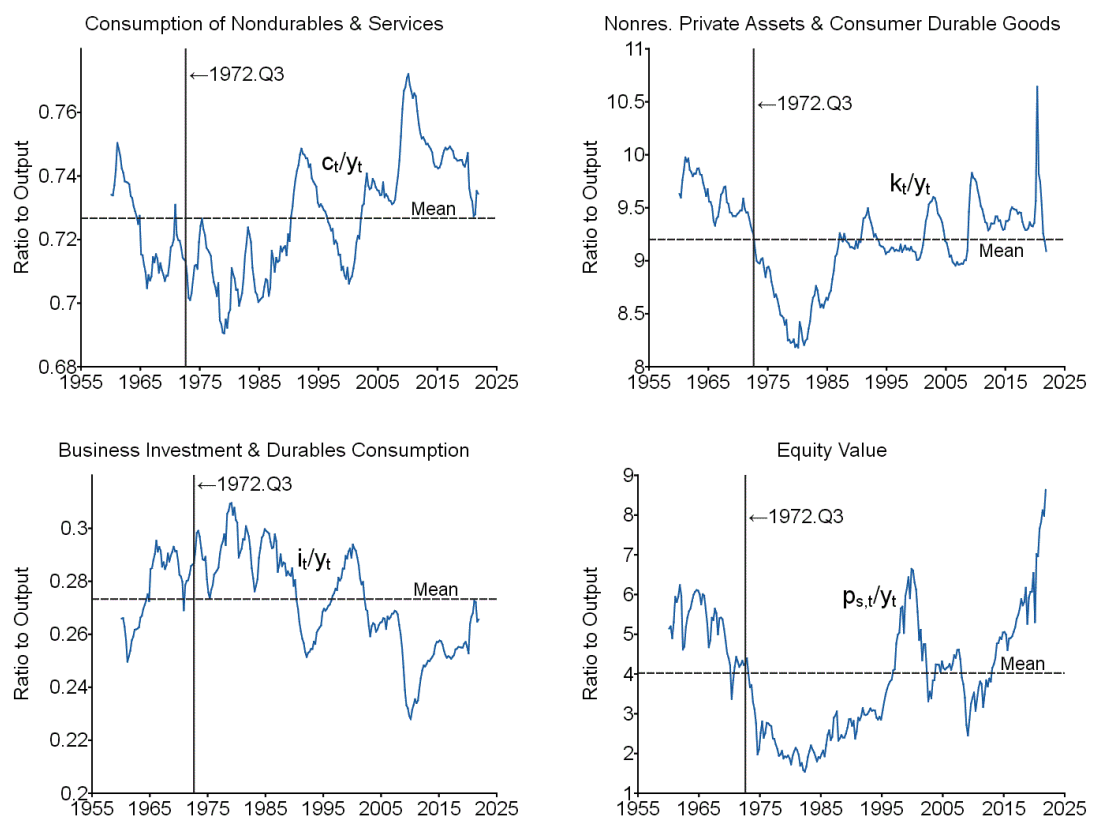

Figure 3: U.S. macroeconomic ratios

Notes: Parameter values are chosen so that the steady state or trend values of model variables are exactly equal to the values observed in the data in 1972.Q3, a period when the ratios of key U.S. macroeconomic variables to output are all close to their full-sample means.

The steady state value $\bar{\eta}=1$ implies $\bar{\kappa}=0$ such that the agent's utility function exhibits no habit component in steady state. The value of $\gamma$ is chosen to deliver an aggregate Frisch labor supply elasticity of $1 / \gamma=1$. This value is consistent with the empirical evidence presented by Kneip, Merz, and Storjohann (2020). Using panel data on German men from 2000 to 2013, they estimate an aggregate Frisch elasticity that ranges between 0.85 and 1.06. Given a time endowment normalized to one, the value of the parameter $D$ achieves the steady state target $h_{1, t}+h_{2, t}=0.3$, implying that the representative agent spends about one-third of available time engaged in market work or investor effort. The values of the parameters $A$ and $B$ achieve the steady state targets of $k_{t} / y_{t}=9.242$ and $k_{t+1} / k_{t}=\exp (\mu)$ when $y_{t}=1$ and $z_{t}=0$, as implied by equations (6) and (11). Table 1 summarizes the model parameter values.

The model-implied values of $p_{s, t} / y_{t}$ and $r_{b, t}$ in 1972.Q3 depend on numerous model parameters, including $\bar{s}, \beta$, and various shock variances which are determined by the data replication exercise (for details, see Appendices A and B). Given candidate shock sequences and their corresponding variances, the values of $\bar{s}$ and $\beta$ are determined iteratively until the model-implied

values. While estimation is typically viewed as more rigorous than calibration, Meenagh, Minford, and Wickens (2021) show that Bayesian and maximum likelihood estimation methods can both deliver significantly biased estimates of the true model's parameter values. 
values for $p_{s, t} / y_{t}$ and $r_{b, t}$ match the corresponding values in U.S. data and the shock sequences have converged. The resulting value $\bar{s}=-0.255$ in 1972.Q3 implies that equity sentiment is "pessimistic" relative to fundamental value in steady state. As noted in the introduction, this feature allows the model to replicate the mean equity risk premium in the data without the need for high levels of risk aversion. In section 4.3, I examine the sensitivity of the model's mean asset returns to alternative values of $\bar{s} .^{23}$

Table 1. Model parameter values

\begin{tabular}{ccl}
\hline \hline Parameter & Value & \multicolumn{1}{c}{ Description/Target } \\
\hline $\bar{\eta}$ & 1 & Risk aversion coefficient $=1$ in 1972.Q3 \\
$\gamma$ & 1 & Frisch labor supply elasticity $=1 / \gamma=1$. \\
$\bar{\alpha}$ & 0.361 & Capital income share $=0.361$ in 1972.Q3. \\
$A$ & 0.999 & $k_{t} / y_{t}=9.242$ with $y_{t}=1$ and $z_{t}=0$ in 1972.Q3. \\
$\bar{\delta}$ & 0.067 & $i_{t} / y_{t}=0.287$ in 1972.Q3. \\
$\bar{\varphi}$ & 0.008 & $d_{t} / y_{t}=0.041$ in 1972.Q3. \\
$B$ & 1.336 & $B\left(i_{t} / k_{t} \delta^{\delta_{t}}\left[\exp \left(z_{t}\right) h_{2, t} / k_{t}\right]_{t}^{\varphi_{t}}=\exp (\mu)\right.$ in 1972.Q3. \\
$D$ & 10.476 & $h_{1, t}+h_{2, t}=0.3$ in 1972.Q3. \\
$\bar{s}$ & -0.255 & $p_{s, t} / y_{t}=4.259$ in 1972.Q3. \\
$\beta$ & 1.002 & $r_{b, t}=0.245 \%$ in 1972.Q3. \\
$\bar{\delta}_{c}$ & 0.945 & $r_{c, t}=0.869 \%$ in 1972.Q3. \\
\hline
\end{tabular}

I solve for the sequences of shock realizations that allow the calibrated model to exactly replicate the observed time paths of eleven U.S. macroeconomic variables and asset returns. These are the ten time series plotted in Figure 2 plus the real return on a long-term U.S. Treasury bond. Of these eleven time series, only nine are independent since $y_{t}=c_{t}+i_{t}$ and $r_{s, t}=\left(p_{s, t}+d_{t}\right) / p_{s, t-1}-1$. The model has nine shocks, so each shock series is uniquely identified. The nine model shocks are: $s_{t}$ (equity sentiment), $\eta_{t}$ (risk aversion), $u_{t}$ (labor disutility), $v_{t}$ (capital law multiplier), $\delta_{t}$ (capital law exponent on investment), $\varphi_{t}$ (capital law exponent on investor effort), $\alpha_{t}$ (factor distribution), $z_{t}$ (labor productivity), and $\omega_{t}$ (bond coupon decay rate). Appendix $\mathrm{C}$ provides the details of the shock identification procedure. ${ }^{24}$

Table 2 shows the values of the shock parameters implied by the identification exercise. All nine shocks exhibit very strong persistence - a typical result in the business cycle literature. ${ }^{25}$ The strong persistence allows model variables that are presumed stationary (e.g., hours worked per person, capital's share of income, and the equity value-consumption ratio) to be able to replicate the sustained upward or downward trends observed in U.S. data. Of the nine total

\footnotetext{
${ }^{23}$ In a similar framework with only six fundamental shocks, Lansing (2019) sets $\bar{s}=0$. That version of the model cannot replicate the U.S. equity risk premium or the risk free rate of return.

${ }^{24}$ For similar shock identification exercises, but in the context of different models, see Lansing and Markiewicz (2018), Gelain, Lansing, and Natvik (2018), Buckman, et al. (2020), and Lansing (2021).

${ }^{25}$ See, for example, Christiano, Motto, and Rostagno (2014, p. 44).
} 
shocks, three can be classified as demand shocks while the remaining six can be classified as supply shocks. I classify the labor disutility shock as one that affects labor supply.

Table 2. Model-identified shock parameters

\begin{tabular}{llll}
\hline \hline \multicolumn{1}{c}{ Shock } & Type & \multicolumn{2}{c}{ Values } \\
\hline Equity sentiment, $s_{t}$ & Demand & $\rho_{s}=0.9249$ & $\sigma_{\varepsilon, s}=0.0738$ \\
Risk aversion, $\eta_{t}$ & Demand & $\rho_{\eta}=0.8585$ & $\sigma_{\varepsilon, \eta}=0.0715$ \\
Labor disutility, $u_{t}$ & Supply & $\rho_{u}=0.8585$ & $\sigma_{\varepsilon, u}=0.0755$ \\
Capital law multiplier, $v_{t}$ & Supply & $\rho_{v}=0.9708$ & $\sigma_{\varepsilon, v}=0.0359$ \\
Capital law exponent on investment, $\delta_{t}$ & Supply & $\rho_{\delta}=0.9802$ & $\sigma_{\varepsilon, \delta}=0.0836$ \\
Capital law exponent on investor effort, $\varphi_{t}$ & Supply & $\rho_{\varphi}=0.9778$ & $\sigma_{\varepsilon, \varphi}=0.1400$ \\
Factor distribution, $\alpha_{t}$ & Supply & $\rho_{\alpha}=0.9793$ & $\sigma_{\varepsilon, \alpha}=0.0135$ \\
Labor productivity, $z_{t}$ & Supply & $\mu=0.0051$ & $\sigma_{\varepsilon, z}=0.0227$ \\
Bond coupon decay rate, $\omega_{t}$ & Demand & $\rho_{\omega}=0.9631$ & $\sigma_{\varepsilon, \omega}=0.0070$ \\
\hline
\end{tabular}

Figure 4 plots the nine model-identified shock sequences. By construction, all shocks are equal to their steady state or trend values in 1972.Q3. ${ }^{26}$ The equity sentiment shock $s_{t}$ mimics movements the U.S. equity valuation ratio, as shown earlier in the top panel of Figure 1 . The sentiment shock fluctuates between -0.85 and -0.01 . The shock reaches its two highest values in 1998.Q2 and 2001.Q4, near the peak of the NASDAQ technology stock boom. The two lowest values occur during the recession quarters of 1982.Q3 and 2009.Q2.

The risk aversion coefficient $\eta_{t}$ fluctuates mildly between 0.64 and 1.24. The maximum value occurs in 2001.Q4 while the minimum value occurs in 1982.Q3. Movements in $\eta_{t}$ are positively correlated with movements in $s_{t}$. As demonstrated below in Section 4.1, this correlation pattern allows the model to match the comovement of U.S. macroeconomic variables over the business cycle.

The labor disutility shock $u_{t}$ exhibits a net downward trend over time, allowing the model to match the net upward trend of total hours worked per person in the data, as shown earlier in Figure 2. The net upward trend in $h_{t}$ occurs despite the net downward trend in labor's share of income $1-\alpha_{t}$ that results from the net increase in the factor distribution shock $\alpha_{t}$. Movements in $u_{t}$ are positively correlated with movements in $s_{t}$ and $\eta_{t}$. This correlation pattern allows the model to match both the amplitude and comovement of macroeconomic variables over the business cycle.

The multiplier shock $v_{t}$ in the capital law of motion (11) is positively correlated with the other two capital law of motion shocks $\delta_{t}$ and $\varphi_{t} \cdot{ }^{27}$ Consequently, $v_{t}$ is almost perfectly

\footnotetext{
${ }^{26}$ The trend value of $z_{t}$ is constructed as $\bar{z}_{t}=\bar{z}_{t-1}+\mu$, where $\mu$ is the sample mean of $\Delta z_{t}$ and $\bar{z}_{t}=z_{t}=0$ in 1972.Q3.

${ }^{27}$ Throughout the paper, I refer to $v_{t}, \delta_{t}$, and $\varphi_{t}$ as the "capital law of motion shocks" because these shocks only appear in equation (11). In contrast, the labor productivity shock $z_{t}$ appears in both equation (6) and equation (11).
} 
negatively correlated with the quantity $1-\delta_{t}-\varphi_{t}$, representing the exponent on $k_{t}$ in the capital law of motion. This correlation pattern allows the model to match the smooth time path of $k_{t}$ in the data while simultaneously matching the more-volatile time paths of $i_{t}$ and $p_{s, t}=i_{t} / \delta_{t}$. Fluctuations in the investor effort shock $\varphi_{t}$ allow the model to match the time path of $d_{t}$ in the data.
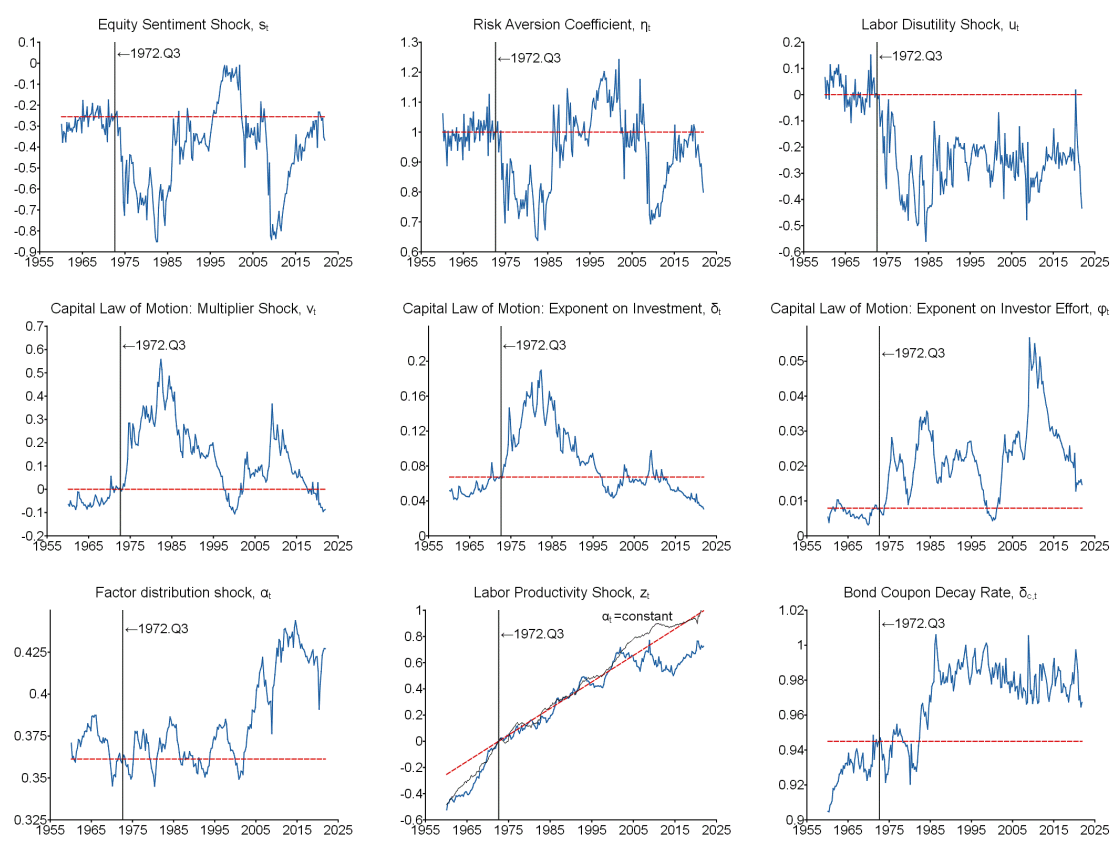

Figure 4: Model-identified shocks

Notes: The sentiment shock is positively correlated with the time-varying risk aversion coefficient $\eta_{t}$ and the labor disutility shock $u_{t}$. The three capital law of motion shocks $v_{t}, \delta_{t}$, and $\varphi_{t}$ are positively correlated with each other. Innovations to first group of shocks are negatively correlated with innovations to the second group. Innovations to the factor distribution shock $\alpha_{t}$ are negatively correlated with innovations to the labor productivity shock $z_{t}$. The bottom middle panel plots an alternative sequence for $z_{t}$ that is identified by an otherwise similar model with $\alpha_{t}=\bar{\alpha}$ for all $t$. The alternative sequence for $z_{t}$ is very different from the model-identified sequence from 2005 onward.

The factor distribution shock $\alpha_{t}$, representing capital's share of income, fluctuates around its steady state value until experiencing a sustained upward trend starting around 2005. As described in Appendix D, $\alpha_{t}$ is measured as one minus the ratio of employee compensation to gross value added of the corporate business sector. The labor productivity shock $z_{t}$ evolves close to trend from around 1970 until the onset of Great Recession in 2008. The shock remains well below trend at the end of the data sample in 2021.Q4. The decline in $z_{t}$ after 2008 partially offsets the concurrent rise in $\alpha_{t}$ so as to replicate the path U.S. output. ${ }^{28}$ Figure

\footnotetext{
${ }^{28}$ Fernald (2014) uses smoothed quarterly data on capital's share of income to identify a quarterly time series
} 
4 also plots an alternative sequence for $z_{t}$ that is identified by an otherwise similar model with $\alpha_{t}=\bar{\alpha}$ for all $t$. The alternative sequence for $z_{t}$ is very different from the model-identified sequence from 2005 onward. Imposing $\alpha_{t}=\bar{\alpha}$ would also yield different sequences for the other model-identified shocks. This example illustrates how the details of the assumed model can strongly influence the patterns of identified shocks.

Finally, the bond coupon decay rate shock $\omega_{t}$ exhibits a net upward trend over time. This pattern allows the model to match the net increase in the U.S. real bond return that derives mainly from the secular decline in U.S. inflation. Movements in $\omega_{t}$ also allow the model to capture the shifting correlation pattern between returns on bonds versus equities, as documented by Campbell, Pflueger, and Viceira (2020).

Table 3 compares the standard deviation of the model-identified shock innovations before and after 1984. ${ }^{29}$ This date corresponds to the approximate start of what had previously been labeled as the "Great Moderation" (e.g., Stock and Watson 2002). For five out of nine shocks, innovation volatility declines in the second sub-sample. But for the remaining four shocks, innovation volatility rises in the second sub-sample. The innovation volatilities for the factor distribution shock and labor productivity shock both exhibit large jumps in the post-1984 sample period. These patterns reflect the imprints of the Great Recession from 2007.Q4 to 2009.Q2 and the Covid recession from 2019.Q4 to 2020.Q2. Overall, the results in Table 3 do not support the notion that macroeconomic or financial volatility has declined markedly in recent decades.

Table 4 shows the contemporaneous cross correlations among the nine shock innovations. There are strong positive correlations between $\varepsilon_{s, t}$ (sentiment), $\varepsilon_{\eta, t}$ (risk aversion), and $\varepsilon_{u, t}$ (labor disutility). There are also strong positive correlations between $\varepsilon_{v, t}, \varepsilon_{\delta, t}$, and $\varepsilon_{\varphi, t}$ (capital law of motion). The first group of innovations is negatively correlated with the second group. There is a strong negative correlation between $\varepsilon_{\alpha, t}$ (factor distribution) and $\varepsilon_{z, t}$ (labor productivity), but these two innovations are mostly weakly correlated with the other innovations. There are sizeable positive correlations between $\varepsilon_{\omega, t}$ (bond coupon decay rate) and the first group of innovations noted above.

for total factor productivity using a Cobb-Douglas production function. The correlation coefficent between $\alpha_{t}$ and Fernald's measure of capital's share is 0.98 .

${ }^{29}$ The shock innovations are computed using the univariate laws of motion for the shocks and the shock parameter values in Tables 1 and 2 . 
Table 3. Standard deviation of shock innovations

\begin{tabular}{cccc}
\hline \hline Innovation & 1960.Q2 to 1983.Q4 & 1984.Q1 to 2020.Q4 & Change \\
\hline$\varepsilon_{s, t}$ & 0.0732 & 0.0742 & $+1.36 \%$ \\
$\varepsilon_{\eta, t}$ & 0.0729 & 0.0704 & $-3.41 \%$ \\
$\varepsilon_{u, t}$ & 0.0771 & 0.0739 & $-4.14 \%$ \\
$\varepsilon_{v, t}$ & 0.0367 & 0.0353 & $-3.95 \%$ \\
$\varepsilon_{\delta, t}$ & 0.0878 & 0.0798 & $-9.20 \%$ \\
$\varepsilon_{\varphi, t}$ & 0.1572 & 0.1286 & $-18.2 \%$ \\
$\varepsilon_{\alpha, t}$ & 0.0119 & 0.0145 & $+21.9 \%$ \\
$\varepsilon_{z, t}$ & 0.0177 & 0.0253 & $+43.3 \%$ \\
$\varepsilon_{\omega, t}$ & 0.0062 & 0.0074 & $+18.6 \%$ \\
\hline
\end{tabular}

Note: Last column is the percent change in volatility from pre- to post-1984 sample periods.

Table 4. Contemporaneous cross correlations of shock innovations

\begin{tabular}{|c|c|c|c|c|c|c|c|c|c|}
\hline Innovation & $\varepsilon_{s, t}$ & $\varepsilon_{\eta, t}$ & $\varepsilon_{u, t}$ & $\varepsilon_{v, t}$ & $\varepsilon_{\delta, t}$ & $\varepsilon_{\varphi, t}$ & $\varepsilon_{\alpha, t}$ & $\varepsilon_{z, t}$ & $\varepsilon_{\omega, t}$ \\
\hline$\varepsilon_{s, t}$ & 1.00 & 0.95 & 0.90 & -0.69 & -0.47 & -0.42 & -0.14 & 0.25 & 0.52 \\
\hline$\varepsilon_{\eta, t}$ & & 1.00 & 0.92 & -0.52 & -0.26 & -0.30 & -0.11 & 0.23 & 0.57 \\
\hline$\varepsilon_{u, t}$ & & & 1.00 & -0.51 & -0.28 & -0.28 & -0.17 & 0.30 & 0.59 \\
\hline$\varepsilon_{v, t}$ & & & & 1.00 & 0.88 & 0.65 & 0.11 & -0.13 & -0.08 \\
\hline$\varepsilon_{\delta, t}$ & & & & & 1.00 & 0.49 & -0.05 & 0.07 & -0.03 \\
\hline$\varepsilon_{\varphi, t}$ & & & & & & 1.00 & 0.45 & -0.37 & -0.07 \\
\hline$\varepsilon_{\alpha, t}$ & & & & & & & 1.00 & -0.89 & -0.22 \\
\hline$\varepsilon_{z, t}$ & & & & & & & & 1.00 & 0.26 \\
\hline$\varepsilon_{\omega, t}$ & & & & & & & & & 1.00 \\
\hline
\end{tabular}

Note: Correlation coefficients computed for the sample period from 1960.Q2 to 2020.Q4.

Recall that the boundedly-rational agent in the model employs univariate forecast rules for each of the nine shocks. A fully-rational agent, in contrast, would employ forecast rules derived from a nine-dimensional vector autoregression (VAR) that captures the complex correlation structure in Table 4. As detailed in Appendix C, the five shocks $\alpha_{t}, z_{t}, v_{t}, \delta_{t}$, and $\varphi_{t}$ are identified directly from the data or from model equilibrium conditions that do not involve the agent's conditional forecasts. The remaining four shocks $s_{t}, \eta_{t}, u_{t}$, and $\omega_{t}$ are identified from model equilibrium conditions that do involve the agent's conditional forecasts, so the assumption of bounded-rationalilty has some influence the resulting sequences for these four shocks. From equations (34) through (41), we can see that imposing $\alpha_{t}=\bar{\alpha}$ for all $t$ would also influence the resulting sequences for other model-identified shocks.

Table 5 examines the potential improvement in forecast accuracy from taking into account the shock correlation structure. Specifically, I compare the accuracy of the model's univariate forecast rules to the accuracy of forecasts derived from a 1-lag VAR estimated on the original model-identified shock sequences for the period 1960.Q3 to 2021.Q4. For six out of the nine shocks, the VAR-based forecasts improve accuracy by less than $10 \%$, as measured by the root 
mean squared forecast error (RMSFE). A portion of the forecast improvements derive from the estimated constant terms in the VAR which are determined by the full-sample average values of the model-identified shocks. In contrast, the constant terms in the univariate forecast rules are pinned down by the steady state or trend values of the shocks in 1972.Q3. As such, the VAR endows the agent with some useful knowledge about the future paths of the shocks. ${ }^{30}$

Table 5: 1-Quarter-Ahead Shock Forecast Accuracy

\begin{tabular}{cccc}
\hline \hline $\begin{array}{c}\text { Forecast } \\
\text { Object }\end{array}$ & $\begin{array}{c}\text { Univariate } \\
\text { RMSFE }\end{array}$ & $\begin{array}{c}\text { VAR } \\
\text { RMSFE }\end{array}$ & $\begin{array}{c}\text { VAR } \\
\text { Improvement }\end{array}$ \\
\hline$s_{t}-\bar{s}$ & 0.074 & 0.070 & $-6.11 \%$ \\
$\log \left(\eta_{t} / \bar{\eta}\right)$ & 0.072 & 0.067 & $-7.22 \%$ \\
$u_{t}$ & 0.082 & 0.070 & $-14.8 \%$ \\
$v_{t}$ & 0.036 & 0.034 & $-4.46 \%$ \\
$\log \left(\delta_{t} / \bar{\delta}\right)$ & 0.084 & 0.081 & $-3.34 \%$ \\
$\log \left(\varphi_{t} / \bar{\varphi}\right)$ & 0.140 & 0.131 & $-5.93 \%$ \\
$\log \left(\alpha_{t} / \bar{\alpha}\right)$ & 0.014 & 0.012 & $-10.6 \%$ \\
$\Delta z_{t}-\mu$ & 0.023 & 0.021 & $-5.18 \%$ \\
$\omega_{t}$ & 0.007 & 0.006 & $-11.9 \%$ \\
\hline
\end{tabular}

Notes: RMSFE $=$ root mean squared forecast error. Univariate forecasts are computed using the shock parameters in Tables 1 and 2. VAR forecasts are computed using a 1-lag VAR estimated on the nine model-identified shocks for the period 1960.Q3 to 2021.Q4.

\section{Quantitative properties of the model}

\subsection{Impulse response functions}

Figure 5 plots impulse response functions from the model. The left column panels show the effects of a one standard deviation positive innovation to $s_{t}$, implying higher sentiment. The innovation causes an immediate increase in output, hours worked, and investment. But since the capital stock cannot respond immediately, the initial increase in output is not sufficient to allow both consumption and investment to increase on impact. Consumption drops on impact, but then increases as the capital stock starts rising in response to higher investment. Equity value increases but bond prices decline.

The middle column panels of Figure 5 show the effects of a one standard deviation negative innovation to $\eta_{t}$, implying less risk aversion. The innovation causes an immediate increase in investment, but total hours worked declines, causing a temporary drop in output and consumption until the capital stock starts rising in response to higher investment. All asset values increase in response to lower risk aversion.

\footnotetext{
${ }^{30}$ For example, the steady state value of the labor disutility shock $u_{t}$ in 1972.Q3 is 0, but the full-sample average value is -0.21 .
} 
Recall from Table 4 that there is a strong positive correlation between the innovations to $s_{t}$ and $\eta_{t}$. The right column panels of Figure 5 show the effects of simultaneous positive innovations to both shocks. Higher sentiment together with higher risk aversion delivers a correlated increase in all macroeconomic variables. Equity value increases but bond prices decline (implying an increase in bond yields). Taken together, the combination of these two highly correlated shocks allows the model to capture the features observed during a typical economic boom or recovery.
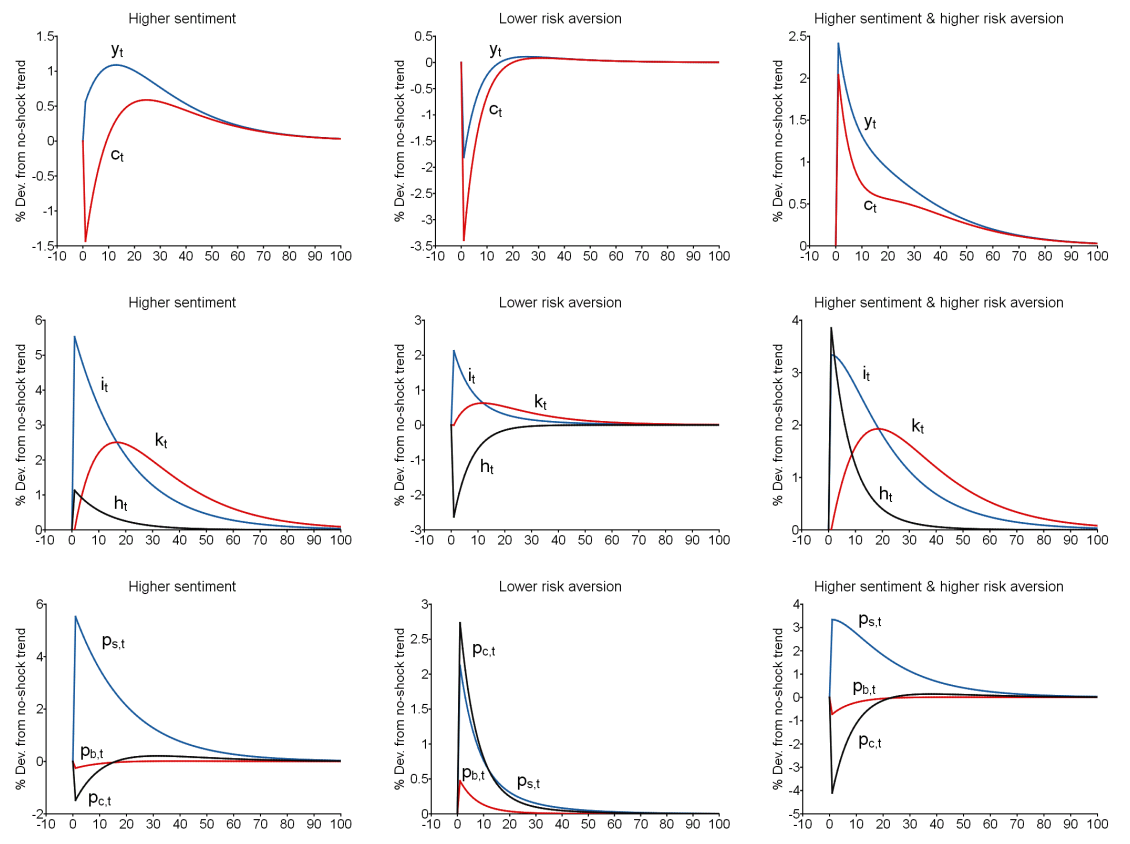

Figure 5: Impulse response functions

Notes: The left column panels show the effects of a positive innovation to the equity sentiment shock $s_{t}$. The middle column panels show the effects of a negative innovation to the risk aversion coefficient $\eta_{t}$. The right column panels show the effects of simultaneous positive innovations to both $s_{t}$ and $\eta_{t}$. Higher sentiment together with higher risk aversion leads to a correlated increase in all macroeconomic variables. Equity value increases but bond prices decline, implying an increase in bond yields.

The combination of higher sentiment and higher risk aversion may seem at odds during an economic boom or recovery. But this combination is what is needed to match the data, according to the model. Recall that higher risk aversion in the model is driven by a higher coefficient $\kappa_{t}$ on the external reference level of consumption. The model-identified value of $\kappa_{t}$ implies that agents place more emphasis on interpersonal consumption comparisons during good times. The fact that model-identified risk aversion is higher during good times provides a partial fundamental justification for investors' higher expectations of future stock market 
returns during good times, as measured by surveys (Figure 1).

Recall that innovations to the labor disutility shock $u_{t}$ are positively correlated with innovations to the sentiment and risk aversion shocks. Adding a simultaneous positive innovation in $u_{t}$ to the exercise in the right column panels of Figure 5 serves to dampen the correlated upward movements in the macroeconomic variables and equity value. The positive correlations among innovations to these three shocks allows the model to replicate both the amplitude and comovement of fluctuations in U.S. macroeconomic variables.

Although not shown, the model can generate similar comovement patterns in response to: (1) a positive innovation to the capital law of motion multiplier shock $v_{t}$, (2) a positive innovation to capital's share of income $\alpha_{t}$, or (3) a positive innovation to the labor productivity shock $z_{t}$. Due to these similar comovement patterns, the model does not identify a "main business cycle shock." I will elaborate further on this point below.
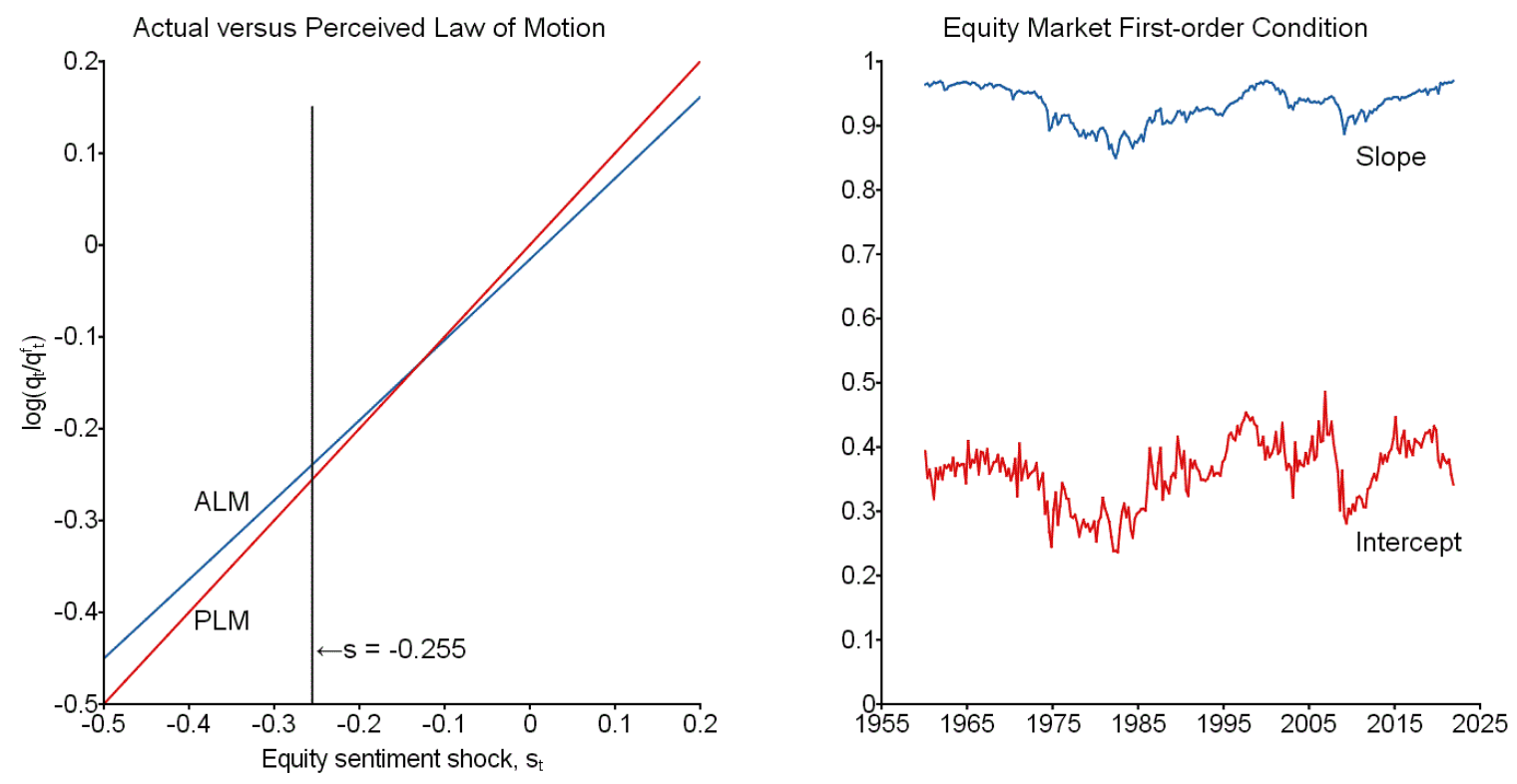

Figure 6: Actual versus Perceived Law of Motion

Notes: The agent's perceived law of motion (28) predicts values for the quantity $\log \left(q_{t} / q_{t}^{\mathrm{f}}\right)$ that are very close to those generated by the actual law of motion. This is because the slope of the equity market first order condition (25) is always close to 1 . Consequently, the agent's perception that equity value is partly driven by sentiment is close to self-fulfilling. 


\subsection{Actual versus perceived law of motion}

Figure 6 provides insight into the near self-fulfilling nature of the agent's perceived law of motion (28). The left panel plots the equilibrium quantity $\log \left(q_{t} / q_{t}^{\mathrm{f}}\right)$ versus the value of the sentiment shock $s_{t}$. For this exercise, all fundamental shocks are set to their steady state values. The agent's perceived law of motion predicts that $\log \left(q_{t} / q_{t}^{\mathrm{f}}\right)$ should increase with $s_{t}$ along the 45-degree line with slope $=1$. The actual law of motion implies that $\log \left(q_{t} / q_{t}^{\mathrm{f}}\right)$ increases along a line with slope $\simeq 0.9$. For any given value of $s_{t}$, the value of $\log \left(q_{t} / q_{t}^{\mathrm{f}}\right)$ predicted by the two lines are nearly the same. For example when $s_{t}=\bar{s}$, the perceived law of motion predicts $\log \left(q_{t} / q_{t}^{\mathrm{f}}\right)=-0.255$ whereas the actual law of motion predicts $\log \left(q_{t} / q_{t}^{\mathrm{f}}\right)=-0.239$. The close approximation of the PLM to the ALM occurs because the slope coefficient applied to the agent's subjective forecast $\widehat{E}_{t} q_{t+1}$ in the transformed first order condition (25) is always close to 1 , as plotted in the right panel of Figure 6. Consequently, the agent's subjective forecast has a very strong influence on the actual value of $q_{t}$.

Table 6 shows that the agent's subjective forecast errors are close to white noise with nearzero mean, giving no obvious signal that the sentiment-based forecast rule (30) is misspecified. The hypothetical model-consistent forecast delivers a slightly lower root mean squared forecast error of 0.614 versus 0.625 for the subjective forecast. ${ }^{31}$ Hence, there is little room for the agent to improve forecasting performance by expending resources to discover the actual law of motion for $q_{t} \cdot{ }^{32}$

Table 6. Properties of equity market forecast errors

\begin{tabular}{lccc}
\hline \hline \multicolumn{1}{c}{ Statistic } & $\begin{array}{c}\text { Subjective } \\
\text { Forecast }\end{array}$ & $\begin{array}{c}\text { Model-consistent } \\
\text { Forecast }\end{array}$ & $\begin{array}{c}\text { Fundamentals-only } \\
\text { Forecast }\end{array}$ \\
\hline Mean $\left(\operatorname{err}_{t}\right)$ & 0.067 & -0.062 & -1.998 \\
$\sqrt{\operatorname{Mean}\left(\operatorname{err}_{t}^{2}\right)}$ & 0.625 & 0.614 & 2.186 \\
$\operatorname{Corr}\left(\operatorname{err}_{t}, \operatorname{err}_{t-1}\right)$ & -0.24 & -0.22 & 0.55 \\
$\operatorname{Corr}\left(\operatorname{err}_{t}, \operatorname{err}_{t-2}\right)$ & 0.08 & 0.08 & 0.61 \\
$\operatorname{Corr}\left(\operatorname{err}_{t}, \operatorname{err}_{t-3}\right)$ & 0.07 & 0.08 & 0.59 \\
\hline
\end{tabular}

Notes: Forecast errors are computed for the sample period 1960.Q2 to 2021.Q4 using the model together with the shock parameters in Tables 1 and 2. The forecast errors are given by $q_{t}-\widehat{E}_{t-1} q_{t}$ (subjective), $q_{t}-E_{t-1}^{m} q_{t}$ (model consistent), and $q_{t}-E_{t-1}^{m} q_{t}^{f}$ (fundamentals only).

The mean value of $q_{t}$ in the model and the data is 5.390 .

\footnotetext{
${ }^{31}$ The model-consistent forecast is constructed from a log-linearized version of the actual law of motion (ALM) for $q_{t}$. The ALM is obtained by substituting the agent's subjective forecast (30) into the transformed first order condition (25). The fundamentals-only forecast in Table 6 is constructed using the fundamental solution (26).

${ }^{32}$ The forecast error statistics in Table 6 are influenced by the small sample properties of the U.S. data and the correlation structure of the shock innovations. In long-run model simulations with othogonal shock innovations, the model-consistent forecast delivers a mean forecast error of -0.012 , a root mean squared forecast error of 0.590 , and a forecast error autocorrelation of 0.00 . The corresponding values for the subjective forecast are $0.055,0.609$, and -0.01 , respectively.
} 
The fundamentals-only forecast performs very poorly when attempting to predict the actual value of $q_{t}$. This is because the representative agent's use of the sentiment-based forecast rule serves to shift the moments of $q_{t}$. From the perspective of any individual agent, switching to the fundamentals-only forecast would appear to reduce forecast accuracy, so there is no incentive to switch. ${ }^{33}$

\subsection{Effect of steady state sentiment}

The value $\bar{s}=-0.255$ allows the model to replicate the equity risk premium in U.S. data while maintaining a low level of risk aversion. Table 7 shows the sensitivity of the model's mean asset returns to higher values of sentiment in each period. Specifically, I shift up the entire sequence of model-identified sentiment shocks by a constant amount so as to achieve the steady state value $\bar{s}^{\prime}>\bar{s}$ in 1972.Q3. The sequences of the eight fundamental shocks are unchanged from the baseline model.

As $\bar{s}^{\prime}$ increases, the equity return $r_{s, t}$ declines. At the same time, both bond returns rise, with the risk free rate $r_{b, t}$ increasing by more than the long-term bond return $r_{c, t}$. Increased optimism serves to shrink, and eventually eliminate, both the mean equity risk premium and the mean bond term premium. For example, when sentiment is neutral in steady state such that $\bar{s}^{\prime}=0$, the mean equity risk premium relative to $r_{b, t}$ is $-0.34 \%$ per quarter. In contrast, the baseline model with $\bar{s}=-0.255$ delivers a mean equity risk premium of $1.77 \%$ per quarter.

Table 7. Effect of steady state sentiment on mean asset returns

\begin{tabular}{lcccccc}
\hline \hline Steady state sentiment & $r_{s, t}$ & $r_{b, t}$ & $r_{c, t}$ & $r_{s, t}-r_{b, t}$ & $r_{s, t}-r_{c, t}$ & $r_{c, t}-r_{b, t}$ \\
\hline $\bar{s}=-0.255$, Baseline model & 2.15 & 0.38 & 1.11 & 1.77 & 1.04 & 0.73 \\
$\bar{s}^{\prime}=-0.1$ & 1.30 & 0.85 & 1.39 & 0.44 & -0.09 & 0.53 \\
$\bar{s}^{\prime}=0$ & 0.83 & 1.16 & 1.58 & -0.34 & -0.75 & 0.42 \\
$\bar{s}^{\prime}=0.1$ & 0.41 & 1.48 & 1.79 & -1.07 & -1.38 & 0.31 \\
$\bar{s}^{\prime}=0.2$ & 0.05 & 1.79 & 2.00 & -1.75 & -1.96 & 0.21 \\
\hline
\end{tabular}

Notes: Each number is the mean quarterly real return (measured in percent) from 1960.Q2 to 2021.Q4 under a given steady state value of the equity sentiment shock in 1972.Q3. The top row shows the mean quarterly returns in U.S. data that are matched in the baseline model with the shock realizations $s_{t}$. Other rows use the shock realizations $s_{t}^{\prime}=s_{t}+\left(\bar{s}^{\prime}-\bar{s}\right)$, such that $s_{t}^{\prime}=\bar{s}^{\prime}$ in 1972.Q3.

\section{Counterfactual shock scenarios}

Figure 7 displays counterfactual shock scenarios for model output $y_{t}$. In the left panel, I add one or more sequences of shock realizations (as indicated) when no other shock realizations are present. In the right panel, I omit one or more sequences of shock realizations while

\footnotetext{
${ }^{33}$ Lansing (2006) explores the concept of "forecast lock-in" using a simple asset pricing model with extrapolative expectations.
} 
leaving the other shock realizations in place. The purpose of these scenarios is to gauge which shock (or set of shocks) has the largest quantitative impact on the path of model output. The capital law of motion shocks $v_{t}, \delta_{t}$, and $\varphi_{t}$ are added or omitted as a group because these shocks all appear in the same model equation and are strongly correlated with each other. I perform similar counterfactual scenarios for other model variables and asset returns.
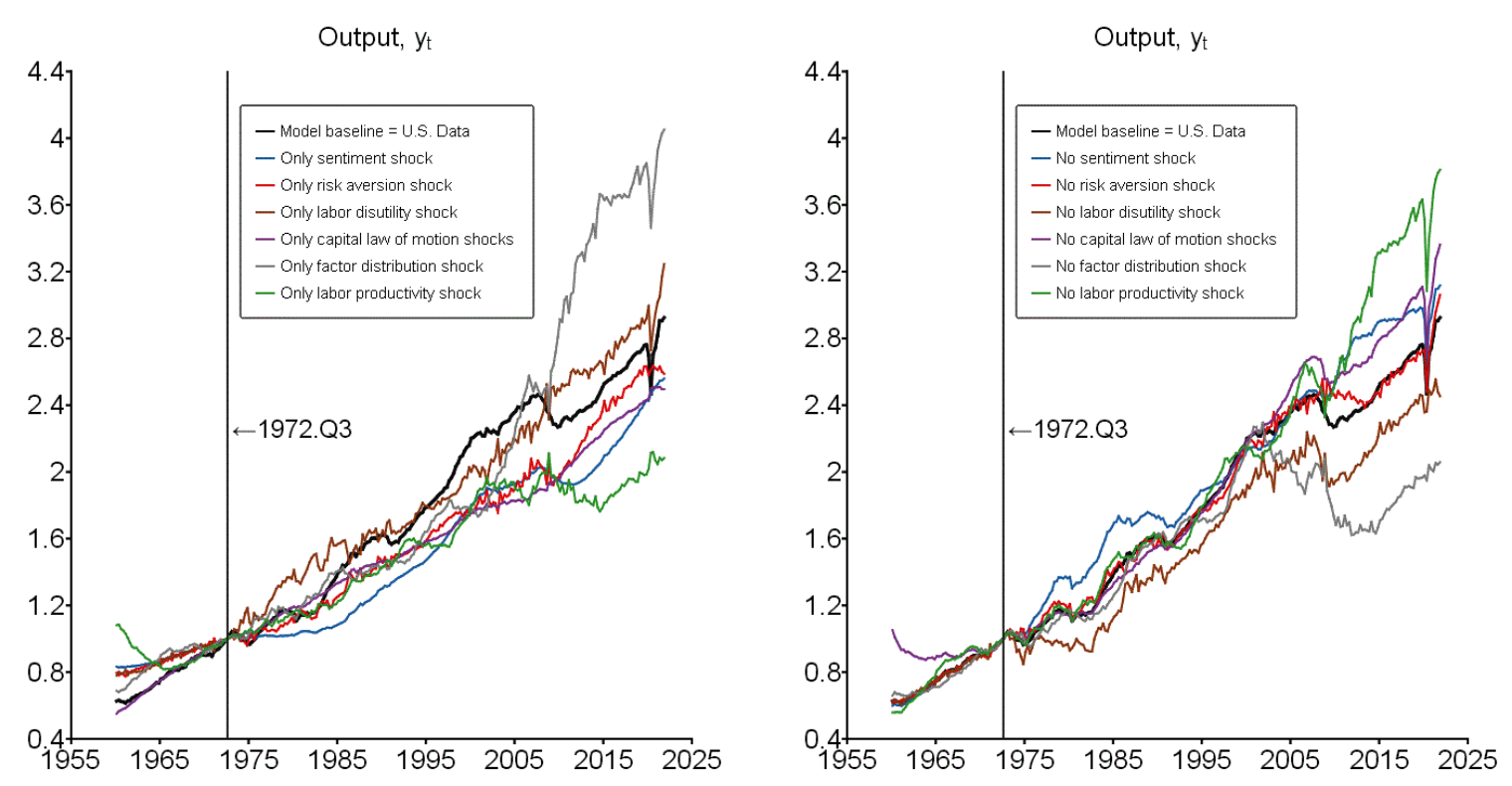

Figure 7: Counterfactual shock scenarios

Notes: The figure displays counterfactual shock scenarios for model output $y_{t}$. In the left panel, I add one or more sequences of shock realizations (as indicated) when no other shock realizations are present. In the right panel, I omit one or more sequences of shock realizations while leaving the other shock realizations in place.

The model solution to the transformed first order condition (25) is log-linear, where $\widehat{E}_{t} q_{t+1}$ is given by equation (30). The agent's forecasts of future shock values that determine the model solution are based on univariate forecast rules, so omitting any given sequence of shock realizations does not affect the model solution or the agent's forecasts for the remaining shocks. When a sequence of shock realizations is omitted, the shock value is set to its steady state value or trend value (in the case of $z_{t}$ ) each period. But any shock innovation variance terms that appear as constants in the model's equilibrium solution remain in place. This procedure ensures that the values of the endogenous variables in 1972.Q3 remain fixed across counterfactual scenarios. ${ }^{34}$

\footnotetext{
${ }^{34}$ For example, equation (30) shows that the value of $\bar{q}$ in 1972.Q3 is influenced by the innovation variance terms.
} 
When a sequence of shock realizations is added, the shock evolves according to the modelidentified path shown in Figure 4. The simulation starts at the model steady state in 1972.Q3 and then uses the model solution to compute the counterfactual values of model variables before and after 1972.Q3. To compute the counterfactual values before 1972.Q3, I invert the capital law of motion (11) to solve for $k_{t}$ as a function of $k_{t+1}, i_{t}, h_{2, t}, v_{t}, \delta_{t}, \varphi_{t}$ and $z_{t}$.

Forecast error variance decompositions are often used to assess the relative importance of different shock innovations in the context of vector autoregressions (Gorodnichenko and Lee 2019). But in these applications, the shock innovations are first orthogonalized, typically via a Choleski decomposition. Forecast error variance decompositions are problematic here because the model-identified shock innovations are not orthogonal to each other, as shown earlier in Table 4. The existence of nontrivial covariances among the shock innovations prevents a clear separation of the variance contribution coming from a given innovation.

As an alternative to forecast error variance decompositions, I compute various summary statistics to gauge the importance of each shock for fluctuations in a given model variable. For fluctuations at business cycle frequencies, I compute the correlation coefficient between the detrended model variable and the detrended U.S. data variable in scenarios that add one or more sequences of shock realizations when no other shock realizations are present. These scenarios are analogous to the "business cycle accounting" exercises presented by Chari, Kehoe, and McGrattan (2007), Šustek (2011), Macnamara (2016), and Brinca, Chari, Kehoe, and McGrattan (2016). But in contrast to these studies, the baseline model here is designed to replicate all movements in the U.S. data, not just those associated with business cycle frequencies. Also in contrast to these studies, I employ a model that allows for stochastic fluctuations in capital's share of income and consider data on U.S. asset returns.

To assess the importance each shock for lower frequency movements in the model variables, I compute the cumulative growth impacts of adding one or more sequences of shock realizations when no other shock realizations are present. I also compute the mean absolute gaps between counterfactual model paths that omit one or more sequences of shock realizations and the corresponding U.S. data paths, without any detrending.

\subsection{Business cycle importance of individual shocks}

Figure 8 compares the detrended path of model output to the detrended path of U.S. output under six different shock scenarios. ${ }^{35}$ The scenarios add one or more sequences of shock realizations when no other shock realizations are present. Table 8 shows the correlation coefficient between the two detrended paths for some key model variables. A large positive correlation coefficient implies that the shock (or set of shocks) being added is an important

\footnotetext{
${ }^{35}$ The detrended paths are constructed by taking logarithms and applying the Hodrick-Prescott filter with a smoothing parameter of 1600 .
} 
driver of business cycle movements in the relevant variable. Similar results are obtained if a shock's importance is judged by regressing the detrended U.S. data on a constant and the detrended model data.
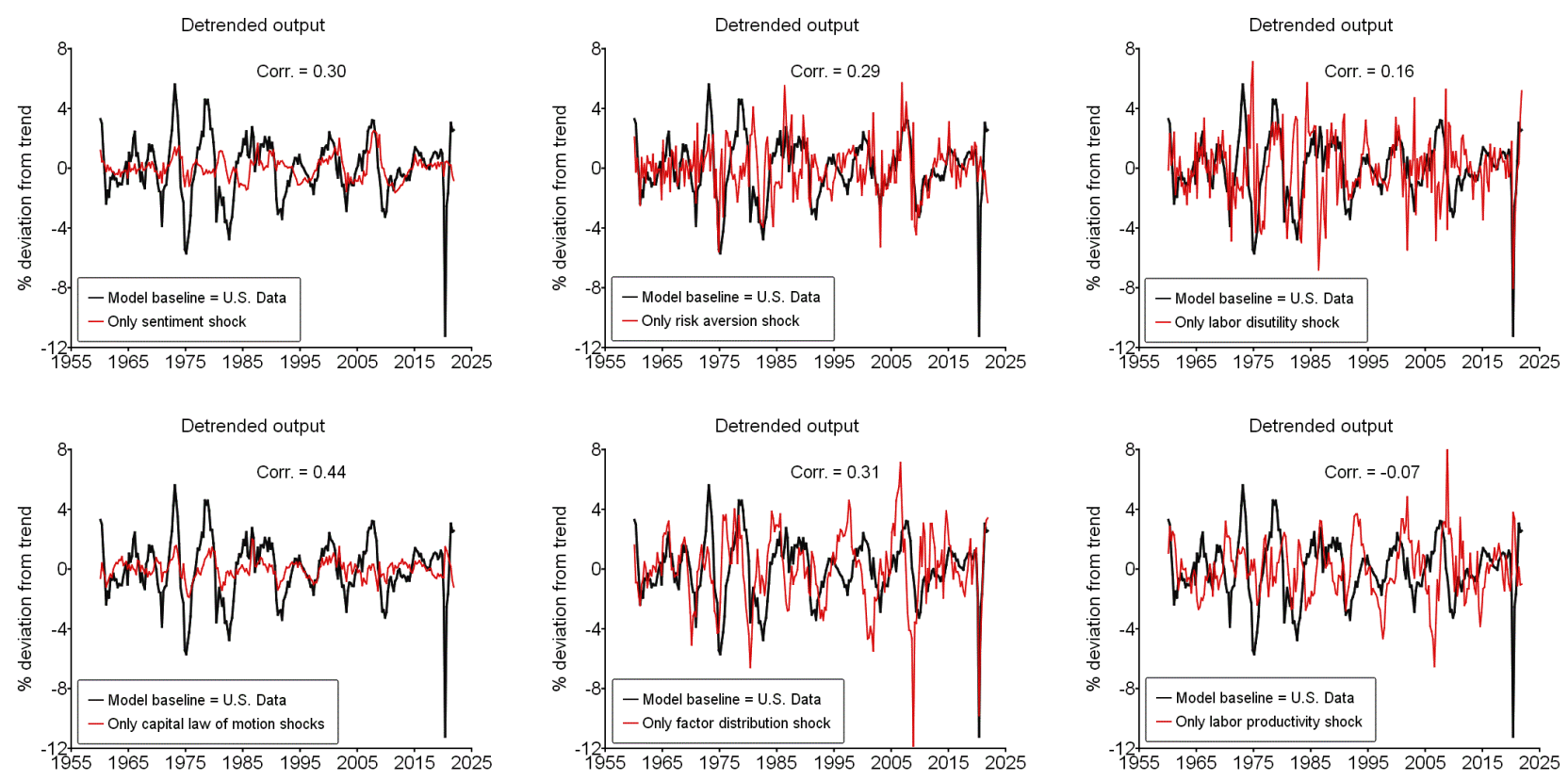

Figure 8: Impacts of individual shocks on detrended output

Notes: The panels compare the detrended path of model output to the detrended path of U.S. output under six different shock scenarios. The scenarios add one or more sequences of shock realizations when no other shock realizations are present. A large positive correlation coefficient implies that the shock (or set of shocks) being added is an important driver of business cycle movements in U.S. output. In four out of the six shock scenarios, the correlation coefficient is sizeable, ranging from 0.29 to 0.44 . This result implies that business cycle movements in U.S. output are driven by multiple types of shocks.

In four of the six shock scenarios, the correlation coefficient for the variable $y_{t}$ is sizeable, ranging from 0.29 to 0.44 . Similarly, there are typically three or more sizeable correlation coefficients (either positive or negative) for the remaining variables in Table 8. According to the model, business cycle movements in the U.S. variables are driven by multiple types of shocks.

In Table 8, the capital law of motion shocks deliver the largest correlation coefficients for the variables $y_{t}, k_{t}$, and $p_{s, t}$. The result for $y_{t}$ is in line with the findings of Justiniano, Primiceri, and Tambalotti (2010) who conclude that "investment shocks" are the main drivers of business cycle movements in output. But in contrast to their results, the capital law of motion shocks identified here are not the main drivers of movements in hours worked. Rather, 
the labor disutility shock delivers the largest correlation coefficient for $h_{t}$. This result is in line with the findings of Chari, Kehoe, and McGrattan (2007). Justiniano, Primiceri, and Tambalotti (2010, p. 133) conclude that "Labor supply shocks are irrelevant over the business cycle, although they dominate the fluctuations of hours at very low frequencies."

Table 8. Model vs. data correlation coefficients: Detrended variables

\begin{tabular}{lrrrrrr}
\hline \hline Shock scenario & \multicolumn{1}{c}{$y_{t}$} & \multicolumn{1}{c}{$c_{t}$} & \multicolumn{1}{c}{$i_{t}$} & \multicolumn{1}{c}{$h_{t}$} & \multicolumn{1}{c}{$k_{t}$} & \multicolumn{1}{c}{$p_{s, t}$} \\
\hline Baseline model = U.S. data & 1.00 & 1.00 & 1.00 & 1.00 & 1.00 & 1.00 \\
Only equity sentiment shock & 0.30 & -0.21 & $\mathbf{0 . 4 3}$ & 0.25 & 0.18 & 0.71 \\
Only risk aversion shock & 0.29 & 0.23 & -0.32 & 0.22 & -0.10 & -0.50 \\
Only labor disutility shock & 0.16 & 0.12 & 0.15 & $\mathbf{0 . 3 7}$ & -0.33 & -0.34 \\
Only capital law of motion shocks & $\mathbf{0 . 4 4}$ & 0.21 & 0.40 & -0.27 & $\mathbf{0 . 4 6}$ & $\mathbf{0 . 9 6}$ \\
Only factor distribution shock & 0.31 & $\mathbf{0 . 3 5}$ & 0.21 & -0.10 & 0.27 & 0.23 \\
Only labor productivity shock & -0.07 & 0.01 & -0.14 & 0.10 & 0.03 & -0.13 \\
\hline
\end{tabular}

Notes: Each number is the correlation coefficient between the detrended path of the model variable under a given scenario and the detrended path of the U.S. data variable. Each scenario adds one or more sequences of shock realizations when no other shock realizations are present. Boldface indicates the largest correlation coefficient for each variable.

Table 8 shows that the equity sentiment shock delivers the largest correlation coefficient for investment $i_{t}$ and the second largest correlation coefficient for equity value $p_{s, t}$. For consumption $c_{t}$, the factor distribution shock and the risk aversion shock deliver the two largest correlation coefficients. Notice that the labor productivity shock delivers near-zero correlation coefficients for all variables in Table 8. This result stands in stark contrast with the findings of Chari, Kehoe, and McGrattan (2007) who employ a model where capital's share of income is constant.

Table 9 shows the correlation coefficients between the model asset returns under a given shock scenario and the corresponding U.S. asset returns (without any detrending). The capital law of motion shocks deliver the largest correlation coefficients for any measure that involves the equity return $r_{s, t}$, including both measures of the equity risk premium $r_{s, t}-r_{b, t}$ and $r_{s, t}-r_{c, t}$. But the sentiment shock also delivers sizeable correlation coefficients for these same return measures. The sentiment shock and the factor distribution shock deliver equally large correlation coefficients for the risk free rate of return $r_{b, t}$. As might be expected, the bond coupon decay shock delivers the largest correlation coefficient for the long term bond return $r_{c, t}$ and the bond term premium $r_{c, t}-r_{b, t}$. Similar to the results in Table 8, the labor productivity shock delivers near-zero correlation coefficients for all of the return measures in Table 9. 
Table 9. Model vs. data correlation coefficients: Asset returns

\begin{tabular}{lrrrrrr}
\hline \hline Shock scenario & $r_{s, t}$ & \multicolumn{1}{l}{$r_{b, t}$} & \multicolumn{1}{c}{$r_{c, t}$} & $r_{s, t}-r_{b, t}$ & $r_{s, t}-r_{c, t}$ & $r_{c, t}-r_{b, t}$ \\
\hline Baseline model = U.S. data & 1.00 & 1.00 & 1.00 & 1.00 & 1.00 & 1.00 \\
Only equity sentiment shock & 0.57 & $\mathbf{0 . 2 8}$ & -0.25 & 0.52 & 0.31 & -0.19 \\
Only risk aversion shock & -0.35 & 0.20 & -0.29 & -0.30 & 0.13 & -0.21 \\
Only labor disutility shock & -0.35 & 0.09 & -0.32 & -0.30 & -0.12 & -0.22 \\
Only capital law of motion shocks & $\mathbf{0 . 9 6}$ & 0.17 & 0.18 & $\mathbf{0 . 9 1}$ & $\mathbf{0 . 6 6}$ & 0.09 \\
Only factor distribution shock & 0.11 & $\mathbf{0 . 2 8}$ & 0.12 & 0.12 & 0.21 & 0.23 \\
Only labor productivity shock & -0.08 & -0.02 & -0.10 & -0.10 & -0.19 & -0.19 \\
Only bond coupon decay shock & 0.06 & 0.02 & $\mathbf{0 . 8 5}$ & 0.02 & 0.46 & $\mathbf{0 . 8 2}$ \\
\hline
\end{tabular}

Notes: Each number is the correlation coefficient between the model asset return under a given scenario and the U.S. asset return. Each scenario adds one or more sequences of shock realizations when no other shock realizations are present. Boldface indicates the largest correlation coefficient for each return measure.

The main takeaway from Tables 8 and 9 is that shocks that appear in the capital law of motion and shocks to equity sentiment are important drivers of short-term movements in most U.S. macroeconomic variables and asset returns. Shocks to risk aversion, labor disutility, and capital's share of income also play a significant role in these movements, but shocks to labor productivity do not.

As a caveat, closer inspection of Figure 8 reveals that the correlation between detrended model output and detrended U.S. output under any given shock scenario can be weak during some recession periods but strong during others. For example, adding only the equity sentiment shock (top left panel of Figure 8) produces a strong correlation with detrended U.S. output during the Great Recession (2007.Q4 to 2009.Q2) but a weak correlation during the Covid recession (2019.Q4 to 2020.Q2). Adding only the labor disutility shock (top right panel of Figure 8) or only the factor distribution shock (bottom middle panel of Figure 8) produces a strong correlation with detrended U.S. output during the Covid recession, but much less so in previous recessions.

\subsection{Great Recession versus Covid recession}

Figure 9 sheds additional light on the most important shocks driving model output during the Great Recession and the Covid recession. Starting from 2007.Q4, I add one or more sequences of shock realizations when no other shock realizations are present. The scenarios show that multiple types of demand and supply shocks contribute to the decline in $y_{t}$ during the Great Recession. These include the sentiment shock (light blue line), the risk aversion shock (red line), the capital law of motion shocks (purple line) and the labor productivity shock (green line). In contrast, the decline in $y_{t}$ during the Covid recession is driven almost entirely by two supply shocks, namely, the factor distribution shock (grey line) and the labor disutility shock (brown line). These results again suggest that there is no most important shock. 
Output, $y_{t}$

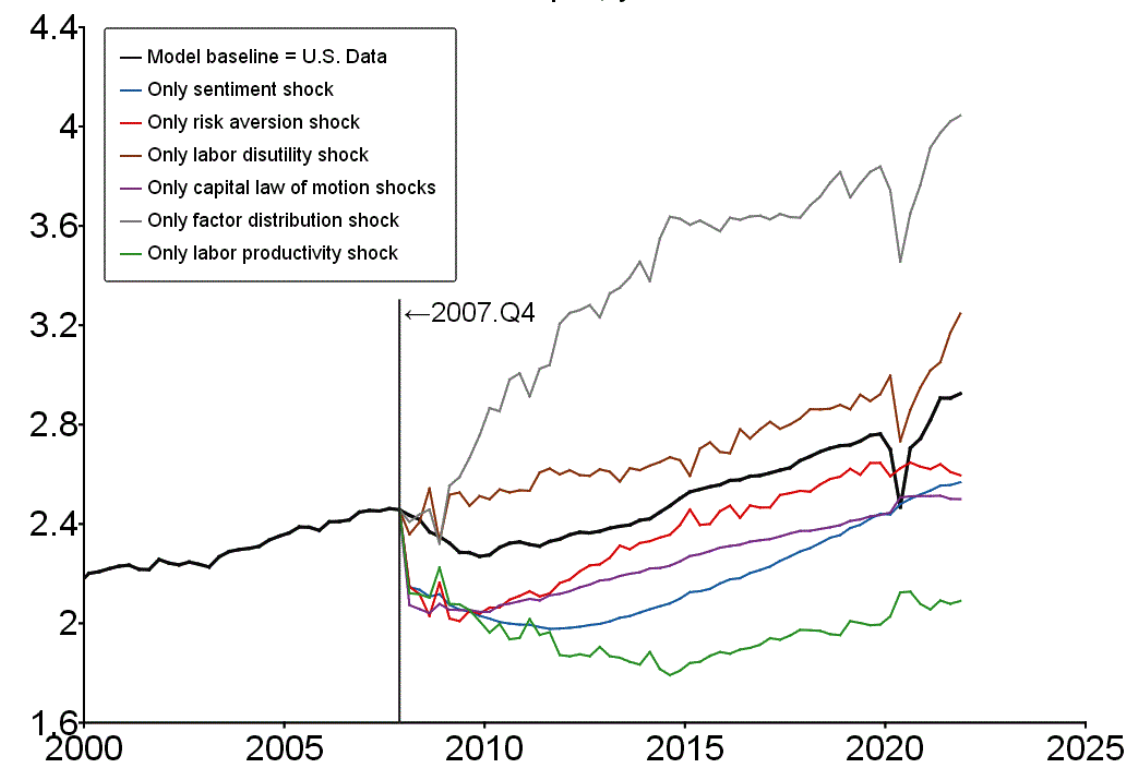

Figure 9: Great recession versus Covid recession

Notes: Starting from 2007.Q4, I add one or more sequences of shock realizations when no other shock realizations are present. Multiple types of demand and supply shocks contribute to the decline in $y_{t}$ during the Great Recession (2007.Q4 to 2009.Q2). These include the sentiment shock (light blue line), the risk aversion shock (red line), the capital law of motion shocks (purple line) and the labor productivity shock (green line). In contrast, the decline in $y_{t}$ during the Covid recession (2019.Q4 to 2020.Q2) is driven almost entirely by two supply shocks, namely, the factor distribution shock (grey line) and the labor disutility shock (brown line).

A recent study by Ferroni, Fisher, and Melosi (2022) synthesize a "Covid shock" within a standard New Keynesian model. Their estimated Covid shock loads on five separate fundamental wedges within the model that impact liquidity preference (as measured by the utility derived from the real value of government bonds), the time discount rate, the marginal efficiency of investment, labor productivity, and inflation. The movements in the fundamental wedges that represent the Covid shock are perfectly correlated by assumption. The Covid shock loads mainly on the liquidity preference wedge and the labor productivity wedge, representing both demand and supply disturbances, respectively. It's important to note, however, that their structural model does not allow for shocks to either capital's share of income or the disutility of labor supply. 


\subsection{Cumulative growth impacts of individual shocks}

Using data from 1952.Q1 to 2017.Q4, Greenwald, Lettau, and Ludvigson (2022) estimate a concentrated capital ownership model with four types of orthogonal shocks that govern: (1) capital owners' share of income, (2) the growth rate of real per capita output, (3) capital owners' degree of risk aversion, and (4) the risk free rate of return. They state (p. 5) "[N]either economic growth, risk premia, nor risk-free interest rates has been the foremost driving force behind the [stock] market's sharp gains over the last several decades. Instead, the single most important contributor has been a string of factor share shocks that reallocated the rewards of production without affecting the size of those rewards."

Table 10 shows the cumulative growth impacts of adding one or more sequences of shock realizations when no other shock realizations are present. Each scenario starts from the model steady state in 1972.Q3. Each number in the table is the cumulative growth rate (in percent) from 1972.Q3 to 2021.Q4. Boldface indicates the largest cumulative growth rate for each macroeconomic variable.

The sequence for the factor distribution shock $\alpha_{t}$ is directly pinned down by U.S. data on capital's share of income. Adding the factor distribution shock alone delivers the largest cumulative growth rate for all variables except total hours worked per person $h_{t}$. The factor distribution shock alone delivers a $305.1 \%$ cumulative increase in real output $y_{t}$, yielding a counterfactual path that is well above the path observed in the data by 2021.Q4 (grey line in top panel of Figure 7). The factor distribution shock alone delivers a $357.7 \%$ cumulative increase in real equity value $p_{s, t}$ versus a $492.8 \%$ cumulative increase observed in the data.

Table 10. Cumulative growth impacts, 1972.Q3 to 2021.Q4

\begin{tabular}{lcccccc}
\hline \hline Shock scenario & $y_{t}$ & $c_{t}$ & $i_{t}$ & $h_{t}$ & $k_{t}$ & $p_{s, t}$ \\
\hline Baseline model = U.S. data & 192.5 & 201.1 & 170.9 & 11.60 & 187.7 & 492.8 \\
Only equity sentiment shock & 155.9 & 163.4 & 137.5 & -1.60 & 137.0 & 137.5 \\
Only risk aversion shock & 158.7 & 145.4 & 192.0 & -7.89 & 179.4 & 192.0 \\
Only labor disutility shock & 224.5 & 224.5 & 224.5 & $\mathbf{2 4 . 1 8}$ & 205.1 & 224.5 \\
Only capital law of motion shocks & 149.5 & 172.7 & 91.82 & 0.60 & 155.6 & 319.8 \\
Only factor distribution shock & $\mathbf{3 0 5 . 1}$ & $\mathbf{2 8 4 . 0}$ & $\mathbf{3 5 7 . 7}$ & -2.09 & $\mathbf{3 2 6 . 2}$ & $\mathbf{3 5 7 . 7}$ \\
Only labor productivity shock & 108.3 & 108.3 & 108.3 & 0 & 111.7 & 108.3 \\
\hline
\end{tabular}

Notes: Each number is the cumulative growth rate (in percent) starting from the model steady state in 1972.Q3 through 2021.Q4. Each scenario adds one or more sequences of shock realizations when no other shock realizations are present. Boldface indicates the largest cumulative growth for each variable.

Recall from Table 4 that the innovation to $\alpha_{t}$ is negatively correlated with the innovation to the labor productivity shock $z_{t}$. Adding a string of mostly positive distribution shock innovations from 2005 onward, while simultaneously omitting a string of mostly negative labor productivity shock innovations from 2008 onward, serves to produce large cumulative 
increases in all model variables except $h_{t}$. Despite different modeling choices and different assumptions regarding the orthogonality of shocks, the results in Table 10 are qualitatively consistent with the findings of Greenwald, Lettau, and Ludvigson (2022).

\subsection{Impacts of omitting shocks without detrending}

Tables 11 and 12 provide an alternative way of assessing the importance of each shock for movements in model variables or asset returns. For these exercises, I omit one or more sequences of shock realizations while leaving the other shock realizations in place. When a particular sequence of shock realizations is omitted, the shock value is set to its steady state or trend value each period. As a result, the path of the model variable will deviate from the path of the U.S. data variable, creating a persistent gap. This pattern can be observed in the right panel of Figure 7. A large gap between the counterfactual model path and the U.S. data path implies that the omitted shock (or set of shocks) plays an important role in allowing the model to replicate the data.

In Table 11, I compute the mean absolute gaps in percent between the counterfactual paths and the U.S. data paths, without any detrending. Omitting the equity sentiment shock or the capital law of motion shocks delivers the largest mean absolute gaps for the variables $i_{t}$, $k_{t}$, and $p_{s, t}$. Recall from Table 8 that adding the equity sentiment shock or adding the capital law of motion shocks delivered the largest correlation coefficients for the detrended versions of these same variables. So, according to the model, the equity sentiment shock and the capital law of motion shocks are clearly very important for explaining all movements in investment, capital, and equity value.

Omitting the labor disutility shock delivers the largest mean absolute gaps for the variables $y_{t}, c_{t}$, and $h_{t}{ }^{36}$ But recall from Table 8 that adding the labor disutility shock alone delivered only small correlation coefficients for the detrended versions of $y_{t}$ and $c_{t}$. This result shows that a particular shock can be important for explaining lower frequency movements in a variable (Tables 10 and 11) but not important for explaining business cycle frequency movements in the same variable (Table 8). Given the large statistical uncertainty surrounding trend-cycle decompositions (Hodrick 2020), these results once again highlight the difficulty of identifying the most important business cycle shock.

Omitting either the factor distribution shock or the labor productivity shock delivers sizable mean absolute gaps for the variables $y_{t}, c_{t}, i_{t}, k_{t}$, and $p_{s, t}$. Relative to the business cycle impacts in Table 8, the labor productivity shock is now much more important for explaining

\footnotetext{
${ }^{36}$ In this scenario, the mean absolute gaps for numerous macroeconomic variables are exactly the same at $10.0 \%$. A similar pattern emerges in the scenario that omits the labor productivity shock. These results are due to log utility which delivers simple proportional relationships among some macroeconomic variables in response to these two shocks.
} 
lower frequency movements in the same variables. Omitting the risk aversion shock delivers relatively small mean absolute gaps for all variables in Table 11. Compared to the results in Table 8, the risk aversion shock is now much less important for explaining lower frequency movements in the variables.

Table 11. Mean absolute gaps: Levels of macroeconomic variables

\begin{tabular}{lcccccc}
\hline \hline Shock scenario & $y_{t}$ & $c_{t}$ & $i_{t}$ & $h_{t}$ & $k_{t}$ & $p_{s, t}$ \\
\hline Baseline model = U.S. data & 0 & 0 & 0 & 0 & 0 & 0 \\
No equity sentiment shock & 7.60 & 4.13 & $\mathbf{2 0 . 8}$ & 3.24 & 18.5 & 20.8 \\
No risk aversion shock & 2.11 & 4.38 & 4.48 & 4.26 & 3.56 & 4.48 \\
No labor disutility shock & $\mathbf{1 0 . 0}$ & $\mathbf{1 0 . 0}$ & 10.0 & $\mathbf{1 0 . 3}$ & 9.91 & 10.0 \\
No capital law of motion shocks & 8.00 & 6.24 & 17.9 & 2.60 & $\mathbf{2 0 . 0}$ & $\mathbf{3 2 . 1}$ \\
No factor distribution shock & 9.95 & 8.70 & 13.5 & 0.48 & 10.4 & 13.5 \\
No labor productivity shock & 8.00 & 8.00 & 8.00 & 0 & 10.5 & 8.00 \\
\hline
\end{tabular}

Notes: Each number is the mean absolute gap in percent between the model path and the U.S. data path under a given scenario that omits one or more sequences of shock realizations. Boldface indicates the largest mean absolute gap for each variable.

For asset returns, Table 12 reports the mean values (in percent) resulting from each shock scenario. Overall, the results portray a complex picture of the roles played by each of the various shocks in generating the mean asset returns observed in the data. Omitting the equity sentiment shock largely eliminates the equity risk premium and mildly shrinks the bond term premium. Omitting the capital law of motion shocks serves to significantly magnify both the equity risk premium and the bond term premium. Omitting the risk aversion shock serves to magnify the equity risk premium but shrink the bond term premium. Omitting the labor disutility shock serves to shrink both the equity risk premium and bond term premium. Omitting the labor productivity shock has little effect on either premium.

Table 12. Counterfactual mean asset returns

\begin{tabular}{lcrrrrc}
\hline \hline Shock scenario & $r_{s, t}$ & \multicolumn{1}{c}{$r_{b, t}$} & $r_{c, t}$ & $r_{s, t}-r_{b, t}$ & $r_{s, t}-r_{c, t}$ & $r_{c, t}-r_{b, t}$ \\
\hline Baseline model = U.S. data & 2.15 & 0.38 & 1.11 & 1.77 & 1.04 & 0.73 \\
No equity sentiment shock & 0.91 & 0.59 & 1.18 & 0.31 & -0.27 & 0.59 \\
No risk aversion shock & 2.93 & 0.88 & 1.30 & 2.04 & 1.63 & 0.42 \\
No labor disutility shock & 2.17 & 1.33 & 1.36 & 0.84 & 0.81 & 0.03 \\
No capital law of motion shocks & 2.15 & -1.69 & 0.57 & 3.85 & 1.58 & 2.27 \\
No factor distribution shock & 1.84 & 0.37 & 1.10 & 1.48 & 0.75 & 0.73 \\
No labor productivity shock & 2.32 & 0.55 & 1.31 & 1.78 & 1.02 & 0.76 \\
No bond coupon decay shock & 2.15 & 0.38 & -0.37 & 1.77 & 2.52 & -0.75 \\
\hline
\end{tabular}

Notes: Each number is the mean quarterly real return (in percent) from 1960.Q2 to 2021.Q4 under a given scenario that omits one or more sequences of shock realizations. The top row shows the mean quarterly returns in U.S. data that are matched by construction in the baseline model. 
Using concentrated capital ownership models (i.e., capital owners versus workers), studies by Greenwald, Lettau, and Ludvigson (2022), Lansing (2015), and Gaudio, Petrella, and Santoro (2022) all identify a large role for shocks to capital owners' share of income in explaining the equity risk premium in U.S. data. In contrast, Table 12 shows that omitting realizations of the factor distribution shock serves only to mildly shrink the mean equity risk premium from $1.77 \%$ in the baseline model to $1.48 \%$ in the counterfactual scenario.

As demonstrated numerically by Lansing (2015, p. 83) and Gaudio, Petrella, and Santoro (2022, p. 30), the equity risk premium in the concentrated capital ownership model is highly sensitive to the presence of factor distribution shocks because these shocks strongly impact the volatility of equity dividends which, in turn, strongly influences the volatility of capital owners' consumption growth. But in an otherwise similar representative agent framework, the same sequence of factor distribution shocks has much less impact on the volatility of the representative agent's consumption growth, thereby muting the resulting impact on the equity risk premium. This example demonstrates that conclusions regarding the relative importance of various shocks for macroeconomic or financial variables can be model-specific.

\subsection{Asset returns from stochastic simulations}

As a final quantitative exercise, I compute asset returns from 100,000 stochastic simulations of the baseline model, where each simulation is 247 quarters in length, i.e., the number of quarters in the data from 1960.Q2 to 2021.Q4. For the simulations, the nine stochastic shocks are orthogonal to each other, as presumed by the theoretical model. The results of the stochastic simulations are presented in Table 15.

Table 15. Distribution of asset returns

\begin{tabular}{ccccccc}
\hline \hline & \multicolumn{3}{c}{ U.S. data } & \multicolumn{3}{c}{ Model simulations } \\
Return & Mean & Median & {$[25 \%, 75 \%]$} & Mean & Median & {$[25 \%, 75 \%]$} \\
\hline$r_{s, t}$ & 2.15 & 3.11 & {$[-2.33,6.90]$} & 1.77 & 1.27 & {$[-5.37,8.35]$} \\
$r_{b, t}$ & 0.38 & 0.37 & {$[-0.21,0.90]$} & 0.27 & 0.19 & {$[-2.61,3.09]$} \\
$r_{c, t}$ & 1.11 & 0.50 & {$[-2.61,4.27]$} & 0.90 & 0.02 & {$[-8.54,9.37]$} \\
\hline \multicolumn{3}{l}{ Notes: Quarterly real returns in percent. U.S. data sample is 1960.Q2 to 2021.Q4. Model } \\
\multicolumn{3}{l}{ statistics are average values from 100,000 simulations, each 247 quarters in length. }
\end{tabular}

The model's $25 \%$ to $75 \%$ distribution bands are quite wide due to the highly persistent nature of the model-identified shocks. This is particularly true for the bands surrounding the simulated long-term bond return $r_{c, t}$. The bond coupon decay shock $\omega_{t}$ has an $\operatorname{AR}(1)$ coefficient of $\rho_{\omega}=0.9631$ and this shock enters directly into the definition of the long-term bond return, as given by $r_{c, t}=\left[1+\bar{\delta}_{c} \exp \left(\omega_{t}\right) p_{c, t}\right] / p_{c, t-1}-1$.

Greenwald, Lettau, and Ludvigson (2022, p. 35) argue that: "high returns to holding equity in the post-war period have been driven, in large part, by a highly unusual sample, one 
characterized by a long string of factors share shocks that redistributed rewards from productive activity toward shareholders."

The results in Table 15 lend support to the idea that the unique set of shock realizations that account for the historical U.S. data sample have produced higher real equity returns than should be expected going forward, based on the theoretical model. The mean and median equity return computed from the model simulations are $1.77 \%$ and $1.27 \%$ per quarter, respectively. Both statistics are below the corresponding values of $2.15 \%$ and $3.11 \%$ observed in U.S. data since 1960. Many of the model-identified shocks plotted in Figure 4 exhibit sustained upward and downward movements that produce a complex correlation structure. Going forward, if the shocks hitting the U.S. economy behave more like the shocks in the theoretical model, then the resulting mean equity return (and the mean equity risk premium) may turn out to be lower than in the past.

\section{Conclusion}

I have used a standard real business cycle model to solve for the sequences of nine stochastic shocks (or wedges) that allow the model to exactly replicate the quarterly time paths of U.S. macroeconomic variables and asset returns since 1960. The model-identified sentiment shock is negative in steady state, allowing the model to match the U.S. equity risk premium with a low level of risk aversion. This feature bears resemblance to asset pricing models with disaster risk. The model-identified risk aversion coefficient is higher in good times, when agents place more emphasis on interpersonal consumption comparisons. This pattern provides a partial justification for investors' higher expectations of future stock market returns during good times, as measured by surveys.

The counterfactual scenarios show that shocks that appear in the law of motion for capital and shocks to equity sentiment are important drivers of business cycle movements in most U.S. macroeconomic variables and asset returns. Shocks to risk aversion, labor disutility, and capital's share of income also play a significant role in these movements, but shocks to labor productivity do not. For lower frequency movements, all of the model-identified shocks can be important, depending on which U.S. variables are being considered.

The model incorporates a shock to capital's share of income which replicates fluctuations of this object in U.S. data. Models that do not allow for such shocks are likely to provide a distorted view of the importance of other model shocks. More generally, conclusions about the most important shock can be strongly influenced by the type of model, or the type of data, used in the exercise. Rather than continuing to search for the elusive "most important shock," it is perhaps time to conclude that U.S. economic outcomes have been shaped by a complex and time-varying mixture of fundamental and non-fundamental disturbances. 


\section{References.}

Abel, A.B. (2002) An exploration of the effects of pessimism and doubt on asset returns, Journal of Economic Dynamics and Control 26, 1075-1092.

Adam, K., A. Marcet, and J. Beutel (2017) Stock price booms and expected capital gains, American Economic Review 107, 2352-2408.

Adam, K. and S. Merkel (2019) Stock price cycles and business cycles, European Central Bank Working Paper 2316.

Adam, K., D. Matveev, and Stefan Nagel (2021) Do survey expectations of stock returns reflect risk adjustments? Journal of Monetary Economics 117, 723-740.

Albuquerque, R., M. Eichenbaum, V.X. Luo, and S. Rebelo (2016) Valuation risk and asset pricing, Journal of Finance 71, 2861-2903.

Ambler, S. and A. Paquet (1994) Stochastic depreciation and the business cycle, International Economic Review 35, 101-116.

Amromin, G., and S.A. Sharpe (2014) From the horse's mouth: Economic conditions and investor expectations of risk and return, Management Science 60, 845-866.

Andrle, M. (2014) Estimating structural shocks with DSGE models, International Monetary Fund, Working Paper.

Andrle, M., J. Brůha, and S. Solmaz (2017) On the sources of business cycles: Implications for DSGE models, European Central Bank Working Paper 2058.

Angeletos, G.-M., F. Collard, and H. Dellas (2018) Quantifying confidence, Econometrica 86, 1689-1726.

Angeletos, G.-M., F. Collard, and H. Dellas (2020) Business-cycle anatomy, American Economic Review 110, 3030-3070.

Ascari, G. and S. Mavroeidis (2022) The unbearable lightness of equilibria in a low interest rate environment, Journal of Monetary Economics 127, 1-17.

Baker, M. and J. Wurgler (2007) Investor sentiment in the stock market, Journal of Economic Perspectives 21(2), 129-152.

Barro, R.J. 2009 Rare disasters, asset prices, and welfare costs, American Economic Review 99, 243-264.

Beaubrun-Diant, K.E. and F. Tripier (2005) Asset returns and business cycles in models with investment adjustment costs, Economics Letters 86, 141-146.

Bernanke, B.S., M. Gertler, and S. Gilchrist (1999), The financial accelerator in a quantitative business cycle framework. In J. Taylor and M. Woodford (eds.), Handbook of Macroeconomics, pp. 1341-1393. Amsterdam: North-Holland.

Bianchi, F., S.C. Ludvigson, and S. Ma (2022) Belief distortions and macroeconomic fluctuations, American Economic Review 112, 2269-2315.

Bidder, R.M. and I. Dew-Becker (2016) Long-run risk is the worst-case scenario, American Economic Review 106, 2494-2527.

Bhandari, A., J. Borovička, and P. Ho (2019) Survey data and subjective beliefs in business cycle models, FRB Richmond Working Paper 19-14.

Brinca, P., V.V. Chari, P.J. Kehoe, and E. McGrattan (2016), Accounting for business cycles. In: J.B. Taylor and H. Uhlig (eds.) Handbook of Macroeconomics, Volume 2A, pp. 1013-1063. Amsterdam: North-Holland.

Buckman, S.R., R. Glick, K.J. Lansing, N. Petrosky-Nadeau, and L.M Seitelman (2020) Replicating and projecting the path of COVID-19 with a model-implied reproduction number, Infectious Disease Modelling 5, 635-651. 
Campbell, J.Y., C. Pflueger, and L.M. Viceira (2020) Macroeconomic drivers of bond and equity risks, Journal of Political Economy 128, 3148-3185.

Campello, M. and J. Graham (2013) Do stock prices influence corporate decisions? Evidence from the technology bubble, Journal of Financial Economics 107, 89-110.

Cecchetti, S.G., P.-S. Lam, and N.C. Mark (2000) Asset pricing with distorted beliefs: Are equity returns too good to be true? American Economic Review 90, 787-805.

Chari, V.V., P.J. Kehoe, and E.R. McGrattan (2007) Business cycle accounting, Econometrica 75, 781-836.

Chirinko, R.S. and H. Schaller (2001) Business fixed investment and 'bubbles': The Japanese case, American Economic Review 91, 663-680.

Christiano, L.J., R. Motto, and M. Rostagno (2014) Risk shocks, American Economic Review 104, 27-65.

Cogley, T. and T.J. Sargent (2008) The market price of risk and the equity premium: A legacy of the Great Depression? Journal of Monetary Economics 55, 454-476.

Cúrdia, V. and R. Reis (2011) Correlated disturbances and the U.S. business cycle, NBER Working Paper 15774.

Danthine, J.-P. and J.B. Donaldson (2002) Labour relations and asset prices, Review of Economic Studies 69, 41-64.

Falter, A. and D. Wesselbaum (2018) Correlated shocks in estimated DSGE models, Economics Bulletin 38, 2026-2036.

Fernald, J.G. (2014) A quarterly, utilization-adjusted series on total factor productivity, FRBSF Working Paper 2012-19.

Ferroni, F., J.D.M. Fisher, and L. Melosi (2022) Unusual shocks in our usual models, FRB Chicago Working Paper 2022-39.

Frydman, R. and J.R. Stillwagon (2018) Fundamental factors and extrapolation in stockmarket expectations: The central role of structural change, Journal of Economic Behavior and Organization 148, 189-198.

Furlanetto, F. and M. Seneca (2014), New perspectives on depreciation shocks as a source of business cycle fluctuations, Macroeconomic Dynamics 18, 1209-1233.

Gaudio, F.S., I. Petrella, and E. Santoro (2022) Supply shocks and asset market participation, Working paper.

Gelain, P., K.J. Lansing, and G.J. Natvik (2018) Explaining the boom-bust cycle in the U.S. housing market: A reverse-engineering approach, Journal of Money Credit and Banking 50, 1751-1782.

Giglio, S., M. Maggiori, J. Stroebel, and S. Utkus (2021). Five facts about beliefs and portfolios, American Economic Review, 111, 1481-1522.

Gilchrist, S., C.P. Himmelberg, and G. Huberman (2005) Do stock price bubbles influence corporate investment? Journal of Monetary Economics 52, 805-827.

Gorodnichenko, Y., and B. Lee (2019) Forecast error variance decompositions with local projections, Journal of Business and Economic Statistics 38, 921-933.

Gourio, F. (2012) Disaster risk and business cycles, American Economic Review 102, 27342766.

Goyal, V.K. and T. Yamada (2004) Asset price shocks, financial constraints, and investment: Evidence from Japan, Journal of Business 77, 175-200.

Greenwald, D.L., M. Lettau and S.C. Ludvigson (2022) How the wealth was won: Factor shares as market fundamentals, Working Paper.

Greenwood, J., Z. Hercowitz, and G.W. Huffman (1988) Investment, capacity utilization, and the real business cycle, American Economic Review 78, 402-417. 
Greenwood, R. and A. Shleifer (2014) Expectations of returns and expected returns, Review of Financial Studies 27, 714-746.

Guvenen, F. (2009) A parsimonious macroeconomic model for asset pricing, Econometrica 77 , 1711-1750.

Hall, R.E. (1997), Macroeconomic fluctuations and the allocation of time, Journal of Labor Economics 15(1), S223-S250.

Hodrick, R.J. (2020) An exploration of trend-cycle decomposition methodologies in simulated data, NBER Working Paper 26750.

Huang, D., F. Jiang, J. Tu, and G. Zhou (2014) Investor sentiment aligned: A powerful predictor of stock returns, Review of Financial Studies 28, 791-837.

Iacoviello, M. (2005) House prices, borrowing constraints, and monetary policy in the business cycle, American Economic Review, 95 739-764.

Jermann, U.J. (1998) Asset pricing in production economies, Journal of Monetary Economics $41,257-275$.

Justiniano, A., G.E. Primiceri, and A. Tambalotti (2010), Investment shocks and business cycles, Journal of Monetary Economics 57, 132-145.

Kaplan, G. and S. Schulhofer-Wohl (2018) The changing (dis-)utility of work, Journal of Economic Perspectives 32(3), 239-258.

Keynes, J. M. (1936), General Theory of Employment, Interest and Money, London: Macmillan.

Kocherlakota, N. (2010) Modern macroeconomic models as tools for economic policy, Federal Reserve Bank of Minneapolis, The Region, pp. 5-21.

Kneip, A., M. Merz, and L. Storjohann (2020) Aggregation and labor supply elasticities, Journal of the European Economic Association 18(5), 2315-2358.

Lansing, K.J. (2006) Lock-in of extrapolative expectations in an asset pricing model, Macroeconomic Dynamics 10, 317-348.

Lansing, K.J. (2010) Rational and near-rational bubbles without drift, Economic Journal 120, 1149-1174.

Lansing, K.J. (2012) Speculative growth, overreaction, and the welfare cost of technologydriven bubbles, Journal of Economic Behavior and Organization 83, 461-483.

Lansing, K.J. (2015) Asset pricing with concentrated ownership of capital and distribution shocks, American Economic Journal-Macroeconomics 7, 67-103.

Lansing, K.J. (2016) On variance bounds for asset price changes, Journal of Financial Markets $28,132-148$

Lansing, K.J. (2019) Real business cycles, animal spirits, and stock market valuation, International Journal of Economic Theory 15, 77-94.

Lansing, K.J. (2021) Endogenous forecast switching near the zero lower bound, Journal of Monetary Economics 117, 153-169.

Lansing, K.J. and S.F. LeRoy (2014) Risk aversion, investor information, and stock market volatility, European Economic Review 70, 88-107.

Lansing, K.J. and A. Markiewicz (2018) Top incomes, rising inequality, and welfare, Economic Journal 128, 262-297.

Lansing, K.J., S.F. LeRoy, and J. Ma (2022) Examining the sources of excess return predictability: Stochastic volatility or market inefficiency? Journal of Economic Behavior and Organization 197, 50-72.

LeRoy, S.F. and R.D. Porter (1981) The present-value relation: Tests based on implied variance bounds, Econometrica 49, 555-577. 
Liu, Z., D.F. Waggoner and T. Zha (2011) Sources of macroeconomic fluctuations: A regimeswitching DSGE approach, Quantitative Economics 2, 251-301.

Macnamara, P. (2016) Understanding entry and exit: A business cycle accounting approach. B.E. Journal of Macroeconomics 16(1), 47-91.

Maurer, J. and A. Meier (2008) Smooth it like the 'Joneses'? Estimating peer-group effects in intertemporal consumption choice, Economic Journal 118, 454-476.

Meenagh, D., P. Minford and M.R. Wickens (2021) Estimating macro models and the potentially misleading nature of Bayesian estimation, CEPR Discussion Paper 15684.

Miao, J., P. Wang, and Z. Xu. (2015) A Bayesian DSGE model of stock market bubbles and business cycles, Quantitative Economics 6, 599-635.

Morley, J.C., C.R. Nelson, and E. Zivot (2003) Why are the Beveridge-Nelson and unobservedcomponents decompositions of GDP so different? Review of Economics and Statistics 85, 235-243.

Nagel, S. and Z. Xu (2022a) Asset pricing with fading memory, Review of Financial Studies $35,2190-2245$.

Nagel, S. and Z. Xu (2022b) Dynamics of subjective risk premia, NBER Working Paper 29803.

Otrok, C., B. Ravikumar, and C.H. Whiteman (2002) Habit formation: A resolution of the equity premium puzzle? Journal of Monetary Economics 49, 1261-1288.

Pigou, A.C. (1927) Industrial Fluctuations, London: Macmillan.

Rietz, T.A. (1988) The equity risk premium: A solution, Journal of Monetary Economics 22, 117-131.

Ríos-Rull, J.V. and R. Santaeulàlia-Llopis (2010) Redistribution shocks and productivity shocks, Journal of Monetary Economics 57, 931-948.

Schmeling, M. (2009) Investor sentiment and stock returns: Some international evidence, Journal of Empirical Finance 16, 394-408.

Shiller, R.J. (1981), Do stock prices move too much to be justified by subsequent changes in dividends? American Economic Review 71, 421-436.

Smets, F. and R. Wouters (2007) Shocks and frictions in U.S. business cycles: A Bayesian DSGE approach, American Economic Review 97, 586-606.

Stock, J.H. and M.W. Watson (2002) Has the business cycle changed and why? In: M. Gertler and K. Rogoff, (eds.), NBER Macroeconomics Annual 2002, pp. 159-218. Cambridge, MA: MIT Press.

Šustek, R. (2011) Monetary business cycle accounting, Review of Economic Dynamics 14, $592-612$.

Vissing-Jørgensen, A. (2004) Perspectives on behavioral finance: Does irrationality disappear with wealth? Evidence from expectations and actions. In: M. Gertler and K. Rogoff, (eds.), NBER Macroeconomics Annual 2003, pp. 139-194. Cambridge, MA: MIT Press.

Welch, I. and A. Goyal (2008) A comprehensive look at the empirical performance of equity premium prediction, Review of Financial Studies 21, 1455-1508.

Young, A.T. (2004) Labor's share fluctuations, biased technical change, and the business cycle, Review of Economic Dynamics 7, 916-931.

Yu, J., 2013. A sentiment-based explanation for the forward premium puzzle, Journal of Monetary Economics 60, 474-491.

Zhu, X. (1995) Endogenous capital utilization, investor's effort, and optimal fiscal policy, Journal of Monetary Economics 36, 655-677. 


\section{Appendix}

\section{A Fundamental equity value}

This appendix provides details of the fundamental solution for $q_{t}^{\mathrm{f}}$ shown in equation (26). First imposing model-consistent expectations and then log-linearizing the right-side of the fundamentals-only version of the transformed first order condition (25) yields

$$
q_{t}^{\mathrm{f}}=\mathrm{b}_{0}\left[\frac{\eta_{t}}{\bar{\eta}}\right]^{\mathrm{b}_{1}}\left[\frac{\alpha_{t}}{\bar{\alpha}}\right]^{\mathrm{b}_{2}}\left[\frac{\delta_{t}}{\bar{\delta}}\right]^{\mathrm{b}_{3}}\left[\frac{\varphi_{t}}{\bar{\varphi}}\right]^{\mathrm{b}_{4}} E_{t}^{m}\left[\frac{q_{t+1}^{\mathrm{f}}}{\bar{q}^{\mathrm{f}}}\right]^{\mathrm{b}_{5}},
$$

where $\mathrm{b}_{i}$ for $i=0$ to 5 are Taylor-series coefficients and $\bar{q}^{\mathrm{f}} \equiv \exp \left[E^{m} \log \left(q_{t}^{\mathrm{f}}\right)\right]$. The expressions for the Taylor-series coefficients are

$$
\begin{aligned}
& \mathrm{b}_{0}=\bar{\alpha} \bar{\eta}+[1-\bar{\delta}(1-\bar{\alpha})-\bar{\varphi}] \beta \bar{q}^{\mathrm{f}}, \\
& \mathrm{b}_{1}=\frac{\bar{\alpha} \bar{\eta}}{\bar{\alpha} \bar{\eta}+[1-\bar{\delta}(1-\bar{\alpha})-\bar{\varphi}] \beta \bar{q}^{\mathrm{f}}}, \\
& \mathrm{b}_{2}=\frac{\bar{\alpha}\left(\bar{\eta}+\bar{\delta} \beta \bar{q}^{\mathrm{f}}\right)}{\bar{\alpha} \bar{\eta}+[1-\bar{\delta}(1-\bar{\alpha})-\bar{\varphi}] \beta \bar{q}^{\mathrm{f}}}, \\
& \mathrm{b}_{3}=\frac{-\bar{\delta}(1-\bar{\alpha}) \beta \bar{q}^{\mathrm{f}}}{\bar{\alpha} \bar{\eta}+[1-\bar{\delta}(1-\bar{\alpha})-\bar{\varphi}] \beta \bar{q}^{\mathrm{f}}}, \\
& \mathrm{b}_{4}=\frac{-\bar{\varphi} \beta \bar{q}^{\mathrm{f}}}{\bar{\alpha} \bar{\eta}+[1-\bar{\delta}(1-\bar{\alpha})-\bar{\varphi}] \beta \bar{q}^{\mathrm{f}}} \\
& \mathrm{b}_{5}=\frac{[1-\bar{\delta}(1-\bar{\alpha})-\bar{\varphi}] \beta \bar{q}^{\mathrm{f}}}{\bar{\alpha} \bar{\eta}+[1-\bar{\delta}(1-\bar{\alpha})-\bar{\varphi}] \beta \bar{q}^{\mathrm{f}}},
\end{aligned}
$$

A conjecture for the fundamental solution takes the form of equation (26). The conjectured solution is iterated ahead one period and then substituted into the right-side of equation (A.1) together with the laws of motion for $\eta_{t+1}, \alpha_{t+1}, \delta_{t+1}$ and $\varphi_{t+1}$ from equations (4), (8), (13) and (14), respectively. After evaluating the model-consistent expectation and then collecting terms, we have

$$
\begin{aligned}
q_{t}^{\mathrm{f}}= & \underbrace{\mathrm{b}_{0} \exp \left[\left(\gamma_{\eta} \mathrm{b}_{5}\right)^{2} \sigma_{\varepsilon, \eta}^{2} / 2+\left(\gamma_{\alpha} \mathrm{b}_{5}\right)^{2} \sigma_{\varepsilon, \alpha}^{2} / 2+\left(\gamma_{\delta} \mathrm{b}_{5}\right)^{2} \sigma_{\varepsilon, \delta}^{2} / 2+\left(\gamma_{\varphi} \mathrm{b}_{5}\right)^{2} \sigma_{\varepsilon, \varphi}^{2} / 2\right]}_{=\bar{q}^{\mathrm{f}}} \\
& \times\left[\frac{\eta_{t}}{\bar{\eta}}\right] \underbrace{\mathrm{b}_{1}+\rho_{\eta} \gamma_{\eta} \mathrm{b}_{5}}_{=\gamma_{\eta}} \times\left[\frac{\alpha_{t}}{\bar{\alpha}}\right] \underbrace{\mathrm{b}_{2}+\rho_{\alpha} \gamma_{\alpha} \mathrm{b}_{5}}_{=\gamma_{\alpha}} \times\left[\frac{\delta_{t}}{\bar{\delta}}\right] \underbrace{\mathrm{b}_{3}+\rho_{\delta} \gamma_{\delta} \mathrm{b}_{5}}_{=\gamma_{\delta}} \times\left[\frac{\varphi_{t}}{\bar{\varphi}}\right] \underbrace{\mathrm{b}_{4}+\rho_{\varphi} \gamma_{\varphi} \mathrm{b}_{5}}_{=\gamma_{\varphi}} \text { (A.8) }
\end{aligned}
$$

which yields five equations in the five solution coefficients $\bar{q}^{\mathrm{f}}, \gamma_{\eta}, \gamma_{\alpha}, \gamma_{\delta}$, and $\gamma_{\varphi}$. For the baseline calibration, the resulting solution coefficients are $\bar{q}^{\mathrm{f}}=7.658, \gamma_{\eta}=0.260, \gamma_{\alpha}=1.071$, $\gamma_{\delta}=-0.653$, and $\gamma_{\varphi}=-0.116$. 


\section{B Equilibrium bond prices}

This appendix outlines the solutions for the equilibrium bond prices $p_{b, t}$ and $p_{c, t}$ using equations (22) and (23). The equilibrium stochastic discount factor can be written as follows

$$
\begin{aligned}
M_{t+1} & =\beta \frac{\eta_{t+1}}{\eta_{t}} \times \frac{c_{t} / y_{t}}{c_{t+1} / y_{t+1}} \times \frac{y_{t}}{y_{t+1}} \\
& =\beta\left[\frac{\eta_{t+1}+\delta_{t+1} x_{t+1}}{\eta_{t}+\delta_{t} x_{t}}\right] \frac{y_{t}}{y_{t+1}},
\end{aligned}
$$

where I have made use of the equilibrium budget relationship $c_{t} / y_{t}=\eta_{t} /\left(\eta_{t}+\delta_{t} x_{t}\right)$ from equation (38).

Making use of equation (6), the term $y_{t} / y_{t+1}$ in equation (B.1) can be written as

$$
\frac{y_{t}}{y_{t+1}}=\frac{\exp \left(z_{t}\right) k_{n, t}^{\alpha_{t}} h_{1, t}^{1-\alpha_{t}}}{\exp \left(z_{t+1}\right) k_{n, t+1}^{\alpha_{t+1}} h_{1, t+1}^{1-\alpha_{t+1}}},
$$

where $k_{n, t} \equiv k_{t} \exp \left(-z_{t}\right)$ is the normalized capital stock, a stationary variable. Starting from equation (11), the law of motion for the normalized capital stock is given by

$$
\begin{aligned}
k_{n, t+1} & =\exp \left(z_{t}-z_{t+1}\right) B \exp \left(v_{t}\right) k_{n, t}^{1-\varphi_{t}}\left[\frac{i_{t}}{y_{t}} \frac{y_{t}}{k_{t}}\right]^{\delta_{t}} h_{2, t}^{\varphi_{t}}, \\
& =\exp \left(z_{t}-z_{t+1}\right) B \exp \left(v_{t}\right) k_{n, t}^{1-\varphi_{t}-\delta_{t}\left(1-\alpha_{t}\right)}\left[\frac{\delta_{t} x_{t}}{\eta_{t}+\delta_{t} x_{t}} A h_{1, t}^{1-\alpha_{t}}\right]^{\delta_{t}} h_{2, t}^{\varphi_{t}} .
\end{aligned}
$$

Equations (35) and (36) can be used to substitute for $h_{1, t}, h_{1, t+1}$, and $h_{2, t}$ in equations (B.2) and (B.3). Then, since $x_{t}$ depends on the equilibrium solution for $q_{t}$, equation (33) can be used to make the substitutions $x_{t}=x\left(\eta_{t}, \alpha_{t}, \delta_{t}, \varphi_{t}, s_{t}\right)$ and $x_{t+1}=x\left(\eta_{t+1}, \alpha_{t+1}, \delta_{t+1}, \varphi_{t+1}, s_{t+1}\right)$ in equations (B.1) through (B.3). After these various substitutions, a log-linear approximation of the stochastic discount factor takes the form

$$
\begin{aligned}
M_{t+1} \simeq & \beta \exp (-\mu)\left[\frac{\eta_{t}}{\bar{\eta}}\right]^{\mathrm{m}_{1}}\left[\frac{\alpha_{t}}{\bar{\alpha}}\right]^{\mathrm{m}_{2}}\left[\frac{\delta_{t}}{\bar{\delta}}\right]^{\mathrm{m}_{3}}\left[\frac{\varphi_{t}}{\bar{\varphi}}\right]^{\mathrm{m}_{4}}\left[\frac{k_{n . t}}{\bar{k}_{n}}\right]^{\mathrm{m}_{5}} \\
& \times \exp \left[\mathrm{m}_{6} v_{t}+\mathrm{m}_{7} u_{t}+\mathrm{m}_{8}\left(s_{t}-\bar{s}\right)+\mathrm{m}_{9} \varepsilon_{\eta, t+1}+\mathrm{m}_{10} \varepsilon_{\alpha, t+1}\right] \\
& \times \exp \left[\mathrm{m}_{11} \varepsilon_{\delta, t+1}+\mathrm{m}_{12} \varepsilon_{\varphi, t+1}+\mathrm{m}_{13} \varepsilon_{z, t+1}+\mathrm{m}_{14} \varepsilon_{u, t+1}+\mathrm{m}_{15} \varepsilon_{s, t+1}\right]
\end{aligned}
$$

where $\mathrm{m}_{1}$ through $\mathrm{m}_{15}$ are Taylor series coefficients and the laws of motions for the shocks have been used to eliminate $\eta_{t+1}, \alpha_{t+1}, \delta_{t+1}, \varphi_{t+1}, z_{t+1}, u_{t+1}$, and $s_{t+1}$. The steady state value of $\bar{k}_{n}$ is given by $k_{t} \exp \left(-\bar{z}_{t}\right)$ in 1972.Q3, where $\bar{z}_{t}$ is the trend value of $z_{t}$ constructed as $\bar{z}_{t}=\bar{z}_{t-1}+\mu$ such that $\mu$ is the sample mean of $\Delta z_{t}$ and $\bar{z}_{t}=z_{t}=0$ in 1972.Q3. Given equation (B.4), it is straightforward to compute $p_{b, t}=E_{t}^{m} M_{t+1}$ and $r_{b, t}=1 / p_{b, t}-1$, where $E_{t}^{m}$ is the model-consistent expectation based on orthogonal shocks. 
The long-term bond pricing equation (23) can be approximated as follows

$$
p_{c, t} \simeq E_{t}^{m} M_{t+1}\left(1+\bar{\delta}_{c} \bar{p}_{c}\right)\left[\frac{p_{c, t+1}}{\bar{p}_{c}}\right]^{\mathrm{b}_{c}} \exp \left(\mathrm{b}_{c} \omega_{t+1}\right)
$$

where $\mathrm{b}_{c}=\bar{\delta}_{c} \bar{p}_{c} /\left(1+\bar{\delta}_{c} \bar{p}_{c}\right)$ is a Taylor series coefficient. A conjectured solution for equation (B.5) takes the form

$$
p_{c, t}=\bar{p}_{c}\left[\frac{\eta_{t}}{\bar{\eta}}\right]^{\mathrm{n}_{1}}\left[\frac{\alpha_{t}}{\bar{\alpha}}\right]^{\mathrm{n}_{2}}\left[\frac{\delta_{t}}{\bar{\delta}}\right]^{\mathrm{n}_{3}}\left[\frac{\varphi_{t}}{\bar{\varphi}}\right]^{\mathrm{n}_{4}}\left[\frac{k_{n . t}}{\bar{k}_{n}}\right]^{\mathrm{n}_{5}} \exp \left[\mathrm{n}_{6} v_{t}+\mathrm{n}_{7} u_{t}+\mathrm{n}_{8}\left(s_{t}-\bar{s}\right)+\mathrm{n}_{9} \omega_{t}\right] .
$$

The conjectured solution (B.6) is iterated ahead one period and then substituted into the approximated long-term bond pricing equation (B.5) together with the expression for $M_{t+1}$ from equation (B.4). Collecting terms and then evaluating the model-consistent expectation operator yields a set of ten equations in the ten solution coefficients given by $\bar{p}_{c}$ and $\mathrm{n}_{1}$ through $\mathrm{n}_{9}$. The value of $\bar{p}_{c}$ depends on the coupon decay parameter $\bar{\delta}_{c}$ and numerous shock variances. Given the shock variances, I solve for the value of $\bar{\delta}_{c}$ such that $p_{c, t}=\bar{p}_{c}=20$ in 1972.Q3. The target value of $\bar{p}_{c}$ is arbitrary and has no affect on the model-implied sequence for the long-term bond return, as given by $r_{c, t}=\left[1+\bar{\delta}_{c} \exp \left(\omega_{t}\right) p_{c, t}\right] / p_{c, t-1}-1$.

\section{Shock identification procedure}

The sequence for the factor distribution shock $\alpha_{t}$ is directly pinned down by U.S. data on capital's share of income. Data for U.S. total hours worked per person $h_{t}$ are plotted in Figure 2. By equating the right-sides of the two equilibrium conditions (16) and (17), the model-implied sequences for $h_{1, t}$ and $h_{2, t}$ are constructed using the following equations

$$
\begin{aligned}
h_{1, t} & =h_{t}\left[1+\left(\varphi_{t} / \delta_{t}\right)\left(i_{t} / y_{t}\right) /\left(1-\alpha_{t}\right)\right]^{-1}=h_{t}\left[\frac{\left(1-\alpha_{t}\right) y_{t}}{y_{t}-d_{t}-i_{t}}\right], \\
h_{2, t} & =h_{t}-h_{1, t}=h_{t}\left[\frac{\alpha_{t} y_{t}-d_{t}-i_{t}}{y_{t}-d_{t}-i_{t}}\right],
\end{aligned}
$$

where I have made use of $w_{t}=\left(1-\alpha_{t}\right) y_{t} / h_{1, t}$ and $d_{t}=\alpha_{t} y_{t}-\left(1+\varphi_{t} / \delta_{t}\right) i_{t}$. The right-side values of $\alpha_{t}, h_{t}, y_{t}, d_{t}$, and $i_{t}$ in equations (C.1) and (C.2) are given by the U.S. data plotted in Figure 2.

Given the model-implied sequences for $h_{1, t}$ and $h_{2, t}$, the sequences for the shocks $z_{t}, \delta_{t}, \varphi_{t}$ and $v_{t}$ are uniquely pinned down using the following equations:

$$
\begin{aligned}
z_{t} & =\left[\log \left(y_{t}\right)-\log \left(A k_{t}^{\alpha_{t}} h_{1, t}^{1-\alpha_{t}}\right)\right] /\left(1-\alpha_{t}\right) \\
\delta_{t} & =i_{t} / p_{s, t} \\
\varphi_{t} & =\delta_{t}\left(\alpha_{t} y_{t}-d_{t}-i_{t}\right) / i_{t} \\
v_{t} & =\log \left(k_{t+1} / k_{t}\right)-\log (B)-\delta_{t} \log \left(i_{t} / k_{t}\right)+\varphi_{t} \log \left[k_{t} \exp \left(-z_{t}\right) / h_{2, t}\right]
\end{aligned}
$$


where the right-side values of the macroeconomic variables are given by the U.S. data plotted in Figure 2. If a shock appears on the right side, then it takes on the value identified in a previous equation. ${ }^{37}$

The sequences for the shocks $u_{t}, s_{t}$, and $\eta_{t}$ are determined iteratively by solving the following set of simultaneous equations

$$
\begin{aligned}
u_{t} & =\log \left\{\eta_{t}\left(1-\alpha_{t}\right) /\left[\left(c_{t} / y_{t}\right) D h_{1, t}\left(h_{1, t}+h_{2, t}\right)^{\gamma}\right]\right\} \\
s_{t} & =\bar{s}-\left(1 / \rho_{s}\right)\left(\bar{s}+\sigma_{\varepsilon, s}^{2} / 2\right)+\left(1 / \rho_{s}\right) \log \left[\eta_{t}\left(p_{s, t} / c_{t}\right) /\left(\beta E_{t}^{m c} q_{t+1}^{\mathrm{f}}\right)\right], \\
\eta_{t} & =\bar{\eta}\left\{p_{b, t} \beta^{-1} \exp (\mu)\left[\alpha_{t} / \bar{\alpha}\right]^{-\mathrm{m}_{2}}\left[\delta_{t} / \bar{\delta}\right]^{-\mathrm{m}_{3}}\left[\varphi_{t} / \bar{\varphi}\right]^{-\mathrm{m}_{4}}\left[k_{n . t} / \bar{k}_{n}\right]^{-\mathrm{m}_{5}}\right. \\
& \times \exp \left[-\mathrm{m}_{6} v_{t}-\mathrm{m}_{7} u_{t}-\mathrm{m}_{8}\left(s_{t}-\bar{s}\right)-\mathrm{m}_{9} \sigma_{\varepsilon, \eta}^{2} / 2-\mathrm{m}_{10} \sigma_{\varepsilon, \alpha}^{2} / 2-\mathrm{m}_{11} \sigma_{\varepsilon, \delta}^{2} / 2\right] \\
& \left.\times \exp \left[-\mathrm{m}_{12} \sigma_{\varepsilon, \varphi}^{2} / 2-\mathrm{m}_{13} \sigma_{\varepsilon, z}^{2} / 2-\mathrm{m}_{14} \sigma_{\varepsilon, u}^{2} / 2-\mathrm{m}_{15} \sigma_{\varepsilon, s}^{2} / 2\right]\right\}^{1 / \mathrm{m}_{1}},
\end{aligned}
$$

where equation (C.7) is the equilibrium labor supply condition (34), equation (C.8) is the equity market first order condition (24), and equation (C.9) is the 1-period bond pricing equation (22) that determines the value of $p_{b, t}$ at the start of quarter $t$. I assume that $p_{b, t}$ in the data is given by the inverse of the U.S. gross risk free rate of return computed from the start of quarter $t$ to the end of quarter $t$. The model-consistent, fundamentals-only forecast $E_{t}^{m} q_{t+1}^{\mathrm{f}}$ that appears in equation (C.8) is computed using the fundamental solution (26). The fundamentals-only forecast depends on the shocks $\eta_{t}, \alpha_{t}, \delta_{t}$, and $\varphi_{t}$.

Various parameters and shock variances that appear in equations (C.8) and (C.9) are initially undetermined, but influence the computed sequences for $u_{t}, s_{t}$, and $\eta_{t}$. These parameters and shock variances include $\bar{s}, \beta, \rho_{s}, \sigma_{\varepsilon, s}, \sigma_{\varepsilon, \eta}$, and $\sigma_{\varepsilon, u}$. Starting from initial guesses for these parameter values and shock variances, together with initial guesses for the sequences of $u_{t}, s_{t}$, and $\eta_{t}$, equations (C.7) through (C.9) are iterated until convergence is achieved. After each iteration, new guesses for the sequences of $u_{t}, s_{t}$ and $\eta_{t}$ are computed as an exponentiallyweighted moving average of the current and past sequences of shock realizations implied by equations (C.7) through (C.9). In practice, convergence to 8 decimal places takes around 75 iterations.

To identify the bond coupon decay rate shock $\omega_{t}$, I first solve the equilibrium bond price solution (B.6) for $\exp \left(\omega_{t}\right)$, yielding

$$
\begin{aligned}
\exp \left(\omega_{t}\right)= & \left\{\left[p_{c, t} / \bar{p}_{c}\right]\left[\eta_{t} / \bar{\eta}\right]^{-\mathrm{n}_{1}}\left[\alpha_{t} / \bar{\alpha}\right]^{-\mathrm{n}_{2}}\left[\delta_{t} / \bar{\delta}\right]^{-\mathrm{n}_{3}}\left[\varphi_{t} / \bar{\varphi}\right]^{-\mathrm{n}_{4}}\left[k_{n . t} / \bar{k}_{n}\right]^{-\mathrm{n}_{5}}\right. \\
& \left.\times \exp \left[-\mathrm{n}_{6} v_{t}-\mathrm{n}_{7} u_{t}-\mathrm{n}_{8}\left(s_{t}-\bar{s}\right)\right]\right\}^{1 / \mathrm{n}_{9}}
\end{aligned}
$$

where $p_{c, t}=\bar{p}_{c}$ in 1972.Q3 such that $\omega_{t}=0$. Next, I substitute equation (C.10) into the definition of the gross bond return given by $1+r_{c, t}=\left[1+\bar{\delta}_{c} \exp \left(\omega_{t}\right) p_{c, t}\right] / p_{c, t-1}$ and then solve

\footnotetext{
${ }^{37}$ Since the computation of $v_{t}$ requires data at time $t+1$, I set the end-of-sample shock value to $v_{T}=\rho_{v} v_{T-1}$, where $T=2021 . \mathrm{Q} 4$.
} 
for $p_{c, t}$. This procedure yields

$$
\begin{aligned}
p_{c, t}= & \left\{\bar{p}_{c}\left[p_{c, t-1}\left(1+r_{c, t}\right) / \bar{\delta}_{c}-1 / \bar{\delta}_{c}\right]^{\mathrm{n}_{9}}\left[\eta_{t} / \bar{\eta}\right]^{\mathrm{n}_{1}}\left[\alpha_{t} / \bar{\alpha}\right]^{\mathrm{n}_{2}}\left[\delta_{t} / \bar{\delta}\right]^{\mathrm{n}_{3}}\left[\varphi_{t} / \bar{\varphi}\right]^{\mathrm{n}_{4}}\left[k_{n . t} / \bar{k}_{n}\right]^{\mathrm{n}_{5}}\right. \\
& \left.\times \exp \left[\mathrm{n}_{6} v_{t}+\mathrm{n}_{7} u_{t}+\mathrm{n}_{8}\left(s_{t}-\bar{s}\right)\right]\right\}^{1 /\left(1+\mathrm{n}_{9}\right)}
\end{aligned}
$$

where $1+r_{c, t}$ is the U.S. gross real bond return in quarter $t$. Given the sequences for the previously-identified shocks, equation (C.11) is used to construct the equilibrium sequence for $p_{c, t}$ for $t>1972$.Q3, starting with $p_{c, t-1}=\bar{p}_{c}$. For $t<1972$.Q3, equation (C.11) is inverted to solve for $p_{c, t-1}$ as a function of $p_{c, t}$ and the previously-identified shocks.

Given the equilibrium sequence for $p_{c, t}$ from 1960.Q1 to 2021.Q4, equation (C.10) is used to recover the model-implied sequence for $\exp \left(\omega_{t}\right)$. The stochastic coupon decay rate is given by $\delta_{c, t} \equiv \bar{\delta}_{c} \exp \left(\omega_{t}\right)$.

\section{Data sources and methods}

I start with data on nominal personal consumption expenditures on nondurable goods plus services $\left(C_{t}\right)$, nominal private nonresidential fixed investment plus nominal personal consumption expenditures on durable goods $\left(I_{t}\right)$, the corresponding chain-type price indices for each of the various nominal expenditure categories that sum to $C_{t}$ and $I_{t}$, and U.S. population. All of this data are from the Federal Reserve Bank of St. Louis' FRED database. I define the nominal ratios $C_{t} / Y_{t}$ and $I_{t} / Y_{t}$, where $Y_{t} \equiv C_{t}+I_{t}$. The nominal ratios capture shifts in relative prices. I deflate $Y_{t}$ by an output price index constructed as the weighted-average of the chain-type price indices for each of the various nominal expenditure categories that sum to $C_{t}$ and $I_{t}$. The weights each period are the categories' nominal expenditure ratios relative to $Y_{t}$. After dividing by U.S. population, the level of real output per person $y_{t}$ is normalized to 1.0 in 1972.Q3. The real per person series for $c_{t}$ and $i_{t}$ are then constructed by applying the nominal ratios $C_{t} / Y_{t}$ and $I_{t} / Y_{t}$ to the constructed $y_{t}$ series. In this way, the real per person series for $c_{t}$ and $i_{t}$ reflect the same resource allocation ratios as the nominal per person series.

Data for $h_{t}$ are hours worked of all persons in the nonfarm business sector from FRED, divided by U.S. population and then normalized to equal 0.3 in 1972.Q3. ${ }^{38}$

The data for $k_{t}$ are constructed using the historical-cost net stock of private nonresidential fixed assets plus the historical-cost net stock of consumer durable goods, both in billions of dollars at year end, from the Bureau of Economic Analysis (BEA), NIPA Table 4.3, line 1 and Table 8.3, line 1, respectively. The data are only available at annual frequency, so I first create a quarterly series by log-linear interpolation. The nominal capital stock series is deflated using the output price index described above and then divided by U.S. population. I normalize the real per person series for $k_{t}$ to deliver a target value of $i_{t} / k_{t}=0.031$ in 1972.Q3. The target value is arbitrary given that the model parameters $B$ and $\bar{\delta}$ can be adjusted to hit

\footnotetext{
${ }^{38}$ The hours data are from https://fred.stlouisfed.org/series/HOANBS.
} 
any desired target value. I choose the target value of $i_{t} / k_{t}$ to coincide with the steady state value implied by a model with no capital adjustment costs, such that $i_{t} / k_{t}=k_{t+1} / k_{t}-1+\delta^{\prime}$, where $k_{t+1} / k_{t}=\exp (0.006)$ is the mean quarterly growth rate of the real capital stock per person series described above and $\delta^{\prime}=0.025$ is a typical quarterly depreciation rate.

I calibrate the value of $A$ in the production function (6) to yield $y_{t}=1$ in 1972.Q3 when $k_{t}$ is equal to the normalized capital stock and $z_{t}=0$ in 1972.Q3. This procedure yields $A=0.9985$ and a sample mean of $k_{t} / y_{t}=9.201$ from 1960.Q1 to 2021.Q4.

Following Lansing (2015) and Lansing and Markiewicz (2018), capital's share of income is measured as one minus the ratio of employee compensation to gross value added of the corporate business sector. Both series are from the BEA, NIPA Table 1.14, lines 1 and 4.

To construct data for $p_{s, t}$, I start with the nominal market capitalization of the S\&P 500 stock index from www.siblisresearch.com. The nominal market capitalization is deflated using the output price index described above and then divided by U.S. population to create a series for real equity value per person.

Quarterly data on the nominal end-of-quarter closing value of the S\&P 500 stock index, nominal dividends, the nominal risk free rate of return (based on a 3-month Treasury bill), and the nominal return on a long-term Treasury bond (based on a maturity of approximately 20 years) are from Welch and Goyal (2008). ${ }^{39}$ The gross nominal return on the S\&P 500 stock index in quarter $t$ is defined as $\left(P_{t}+D_{t} / 4\right) / P_{t-1}$, where $P_{t}$ is the end-of-quarter closing value of the index and $D_{t}$ is cumulative nominal dividends over the past 4 quarters. Gross nominal asset returns are converted to gross real returns by dividing by $1+\pi_{t}$ where $\pi_{t}$ is the quarterly inflation rate computed using the output price index described above. Given the gross real equity return $1+r_{s, t}$ and the constructed data for real equity value per person $p_{s, t}$, I compute a consistent series for real dividends per person as $d_{t}=\left(1+r_{s, t}\right) p_{s, t-1}-p_{s, t}$. The gross nominal returns on the 3-month Treasury bill and the long-term Treasury bond are similarly divided by $1+\pi_{t}$ to obtain the gross real bond returns $1+r_{b, t}$ and $1+r_{c, t}$.

The consumer sentiment series plotted in Figure 1 is from the University of Michigan's Survey of Consumers. ${ }^{40}$ The survey data on investors' expected stock returns over the next year is from Nagel and $\mathrm{Xu}(2022 \mathrm{a}) .{ }^{41}$ The series is constructed by combining information from the UBS/Gallup survey, the Conference Board survey, the University of Michigan's Survey of Consumers, plus several smaller surveys of brokerage and investment firm customers.

\footnotetext{
${ }^{39}$ Updated data through the end of 2021 are available from Amit Goyal's website: https://sites.google.com/view/agoyal145.

${ }^{40}$ See www.sca.isr.umich.edu/tables.html.

${ }^{41}$ The data are available from https://voices.uchicago.edu/stefannagel/code-and-data/.
} 